\title{
7. Adsorption Processes on Zeolites and Metal-Organic Frameworks for Industrial and Environmental Applications
}

Elena López-Maya, ${ }^{1}$ Carmen Montoro, ${ }^{2}$

L. Marleny Rodriguez-Albelo ${ }^{1}$ and Carmen R. Maldonado ${ }^{1}$

${ }^{1}$ Universidad de Granada, Departamento de Química Inorgánica, Avda. Fuentenueva s/n, 18071 Granada, Spain.

${ }^{2}$ Universidad Autónoma de Madrid, Departamento de Química Inorgánica, C/ Tomás y Valiente $\mathrm{n}^{\circ} 7,28049$ Madrid, Spain.

Keywords: Adsorption, gas storage, harmful gases, greenhouse gases, pollutant, wastewater

\section{Introduction}

This Chapter discusses, the impact that inorganic porous matrixes (namely, zeolites and metal-organic frameworks) have on industrial development and environmental remediation processes. In particular, the role of these materials as adequate adsorbents for gas storage, air purification, gas mixture separation or wastewater treatment is thoroughly analysed. In fact, zeolites and metal-organic frameworks (MOFs) exhibit exceptional features, mainly due to their high surface area and tunability, which make them ideal candidates for these types of application, outperforming, in some cases, the classic porous materials. Thus, the basic principles of the adsorption process, as well as the main strategies employed to enhance the adsorptive properties (capacity and selectivity) of these porous matrixes is presented. In particular, we focus attention on those methodologies capable of modifying the final characteristics (size and functionality) of the pores and/or frameworks and, therefore, able to adapt the adsorption properties and selectivity of the resulting materials to a specific application or adsorbate. The gas adsorption properties of zeolites and MOFs are outlined focusing on suitable applications of each gas. These include energy $\left(\mathrm{H}_{2}, \mathrm{CH}_{4}\right)$, environmental $\left(\mathrm{CO}_{2}, \mathrm{NOx}, \mathrm{SOx}, \mathrm{etc}\right)$ and 
other gases $\left(\mathrm{O}_{2}\right.$ and noble gases $)$ purification and separation. Finally, the adsorption capacity of these materials towards different pollutants present in water, such as heavy metals, radionuclides, dyes, pharmaceuticals and other toxic organic molecules, is also discussed, including the most representative examples found in recent literature.

\section{Principles of adsorption processes}

The term adsorption was introduced by Kaiser in 1881 to describe the surface phenomenon that occurs at the interface of a solid (adsorbent) and a fluid phase (adsorbate) due to the interaction forces that appear between the solid and the molecules of the fluid phase (gas, vapour or liquid). In contrast, when the adsorbed molecules return to the fluid phase the phenomenon of desorption occurs. If the adsorbate is exposed to an adsorbent for a certain period of time, a dynamic equilibrium between the number of adsorbed and desorbed molecules by the material takes place (Figure 1). It is important not to confuse this phenomenon with the phenomenon of absorption, which appears when the molecules of a gas or liquid phase are incorporated into the volume of the solid phase.

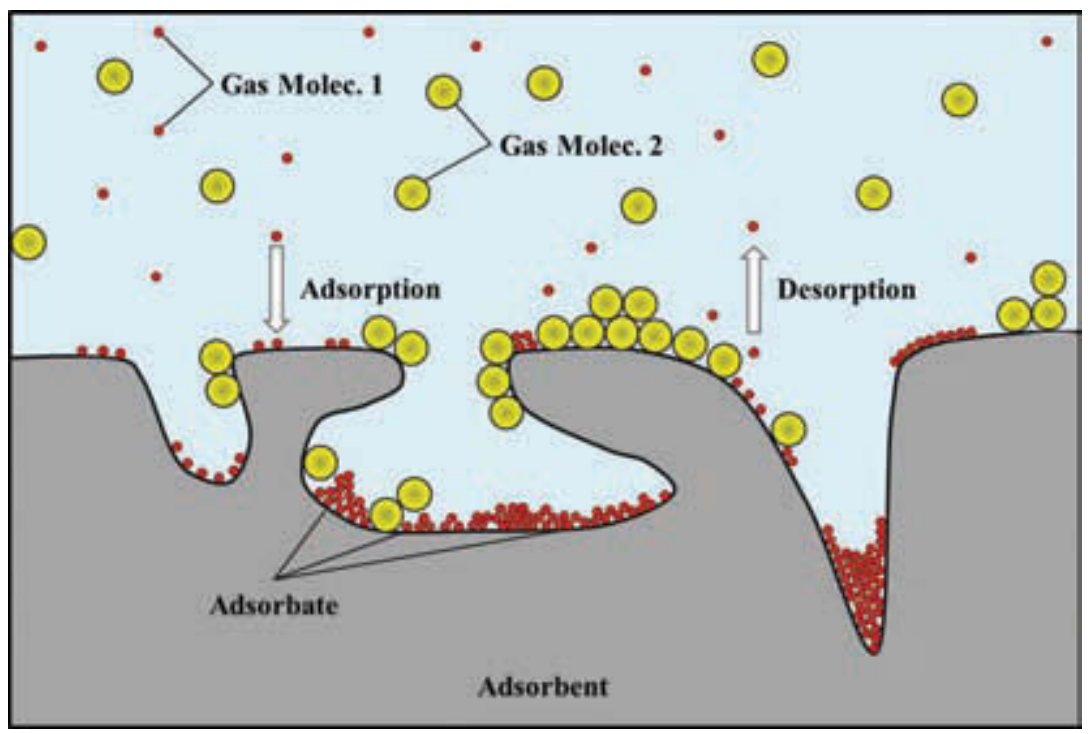

Figure 1. Schematic representation of a gas-solid adsorption process. 

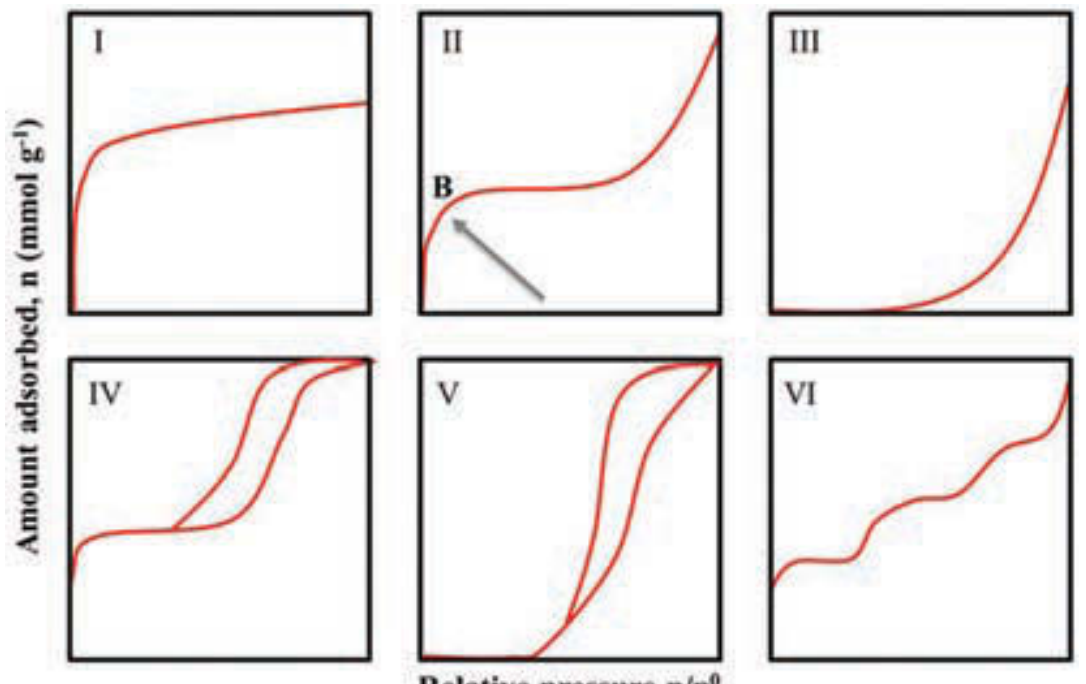

Relative pressure $\mathbf{p} / \mathbf{p}^{0}$

Figure 2. Types of adsorption isotherms according to IUPAC classification.

The interaction forces between both phases can be of a physical and chemical nature, giving rise to physisorption and chemisorption phenomena, respectively [1]. The main difference between both processes is that while physisorption is characterized by weak and reversible interactions, chemisorption is characterized by strong, generally irreversible bonds, and the formation of a new compound. In this chapter, we focus on the physisorption phenomena. In order to do this, it is very important to know different characteristic parameters of a porous matrix in order to show their potentialities in gas storage, capture, and separation processes.

One of these parameters is the quantification of the gas adsorbed on the surface of a solid at a given temperature by the measurement of its adsorption isotherm. This measurement represents the amount of gas adsorbed as a function of the gas pressure in equilibrium with the solid. Adsorption isotherms can be classified, according to the IUPAC recommendations, in six different types: I to VI (Figure 2) [1,2]. The first five types of the classification (I to V) were originally proposed by S. Brunauer, L. S. Deming, W. E. Deming and E. Teller, and constitute the classification BDDT, [3-5] also called the Brunauer classification.

The isotherms types are described as follows:

- Type I isotherm is characteristic of microporous materials, such as activated carbons, zeolites and MOFs, since it shows the filling of the 
micropores at very low relative pressures until reaching a limit value corresponding to the coating of the surface by a monolayer. The predominating interactions are adsorbate-adsorbent.

- Type II isotherm corresponds to the typical adsorption of macroporous solids, showing the formation at low pressures of a monolayer (near point B) and the subsequent formation of the multilayer, with a thickness increasing under pressure. When the pressure reaches saturation, the adsorbed layer corresponds to that of the liquid. The adsorbate-adsorbent interactions are stronger than the adsorbate-adsorbate interactions.

- Type III isotherm describes the adsorption processes of non-porous solids, like metal solids, where adsorbate-adsorbent interactions are weaker than adsorbate-adsorbate interactions.

- Type IV isotherm is characterized by the presence of hysteresis cycles (adsorption and desorption curves do not follow the same trajectory). It describes the adsorption behaviour of mesoporous materials, such as silica and alumina, which are filled by capillary condensation.

- Type $\mathrm{V}$ isotherms are uncommon and difficult to interpret. The affinity of the adsorbent (porous in this case, in contrast to type III) by the adsorbate is low and the hysteresis links with the filling of the pores. It is typical of the adsorption of water vapour at temperatures close to the environment.

- Type VI isotherm describes the adsorption in multilayer of noble gases on highly uniform surfaces. Each of the first layers is adsorbed within a certain range of pressures, each step corresponding to the filling of a monolayer, up to a total of two or three layers. These are cooperative adsorption processes that contribute to each layer, helping the formation of the next through lateral interactions of the molecules themselves.

Furthermore, prior to the measurement of the adsorption isotherm, an activation of the material is required. In particular, this process consists of the evacuation of the solvent molecules, coming from the synthesis or even from the atmosphere, by applying appropriate temperature and vacuum conditions. In this sense, the required temperature is determined by the corresponding thermogravimetric analysis.

Adsorption isotherms provide very important information about specific surface area, pore volume, and even about the distribution of pore sizes. The determination of these textural properties is performed through the analysis of the isotherm, by adjusting the experimental curve to a mathematical expression that represents an approximate model for the adsorption process of the molecules on the surface. The most widely used models for MOFs and zeolites are the Langmuir model and the Brunauer-Emmet-Teller 
(BET). The determination of the surface area of MOFs and zeolites is calculated by the measurement of the $\mathrm{N}_{2}$ adsorption isotherm at $77 \mathrm{~K}$ and is then interpreted with the BET model in the range of low relative pressures $\left(p_{r}=p / p^{\circ}, p^{\circ}\right.$ being the saturation vapour pressure $)$, usually $0.05-0.30[6]$. In other cases, when the volume or adsorption capacity of the micropores is concerned, the $\mathrm{CO}_{2}$ adsorption isotherm is measured at $273 \mathrm{~K}$ and the Dubinin-Radushkevich method is used [5,7].

Another important parameter that must be known when establishing the possible application of a material is the enthalpy of adsorption. This magnitude provides information on the affinity of the pore surface for the adsorbate molecules and the energy required for its removal during the regeneration of the adsorbent. Generally, the enthalpy of adsorption is measured as an isosteric heat of adsorption (meaning that it is determined at a fixed amount of adsorbent, see below) and is a function of the amount of adsorbed adsorbate on the surface. Its determination can be carried out either statically, by isosteric methods or dynamically, by the inverse gas chromatography (IGC) technique [8-10], both methods use the ClausiusClapeyron equation (1) to determine the isosteric heat of adsorption.

$$
\Delta H_{a d s}=-R\left(\frac{\partial \ln p}{\partial\left(\frac{1}{T}\right)}\right)_{N}
$$

where $\Delta \mathrm{H}_{\mathrm{ads}}$ is the enthalpy of adsorption, $\mathrm{p}$ is the adsorbate partial pressure, $\mathrm{T}$ is the temperature, $\mathrm{N}$ is the amount of adsorbed gas, and $\mathrm{R}$ is the gas constant.

\section{Isosteric method}

The isosteric method consists of the measurement of at least two adsorption isotherms at different temperatures (Figure 3, where $\mathrm{T}_{1}>\mathrm{T}_{2}$ ) and the application of the Clausius-Clapeyron equation. This method assumes that the adsorbed phase remains unchanged and in thermodynamic equilibrium, at the temperature range studied. Linearizing equation (1) to an Arrhenius equation, equation (2) is obtained, from which we can calculate the value of $\Delta \mathrm{H}_{\text {ads }}$, which is the slope of the line representing the natural logarithm of the partial pressure $\ln \mathrm{p}$, for a constant value of the amount of gas adsorbed, versus the inverse of the temperature $1 / \mathrm{T}$. 


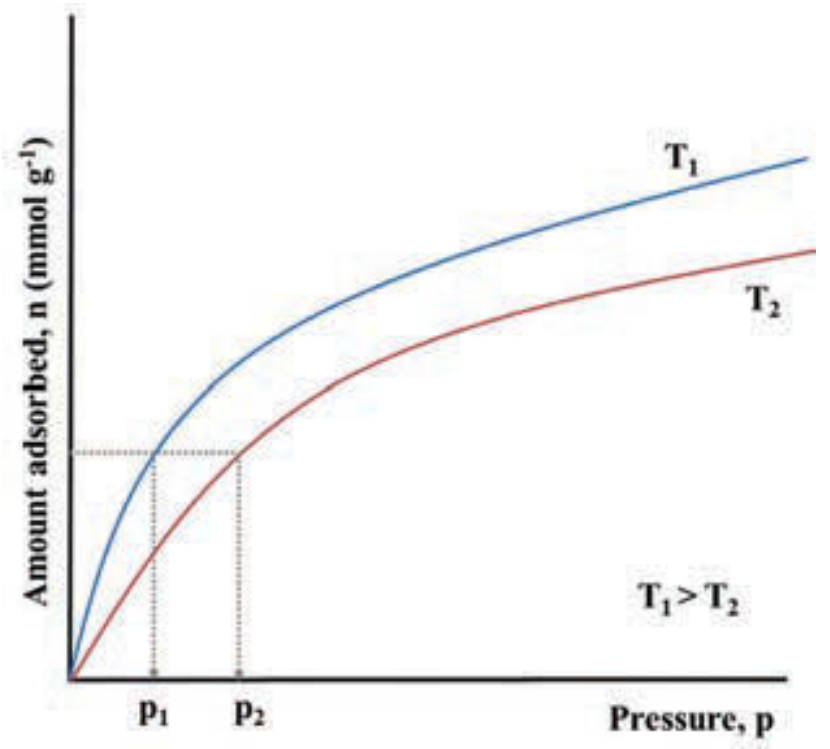

Figure 3. Determination of adsorption heat by isosteric methods.

$$
(\ln p)_{N}=-\frac{\Delta H_{a d s}}{R T}+C
$$

\section{Chromatographic methods}

As mentioned earlier, it is considered that the adsorption under dynamic conditions and at temperature is more realistic and it generally differs from the adsorption at ambient temperature [11-13]. Inverse Gas Chromatography (IGC) is essentially analogous to conventional gas chromatography with the exclusive difference, and hence the inverse term, that the object of interest is the stationary phase formed by the porous material in the form of a pellet to avoid pressure drops (Figure 4) $[12,14]$. IGC is based on an adsorption process at infinite dilution (or zero coverage), that is, at very low adsorbate vapour partial pressures. Under these conditions, the solute concentration is very low, the adsorbate-adsorbate side interactions are negligible, and the adsorption enthalpy depends only on the adsorbate-adsorbent interactions. IGC also allows establishing, for each adsorbate, the thermodynamic parameters of the adsorption process, that is, the Henry constants, $\mathrm{K}_{\mathrm{H}}$, and adsorption heats, $\Delta \mathrm{H}_{\text {ads' }}$ as well as the partition coefficients, $\alpha_{x / y}$, which will determine the selectivity of the material towards a given adsorbate, $\mathrm{X}$, compared to another one, $\mathrm{Y}$. 


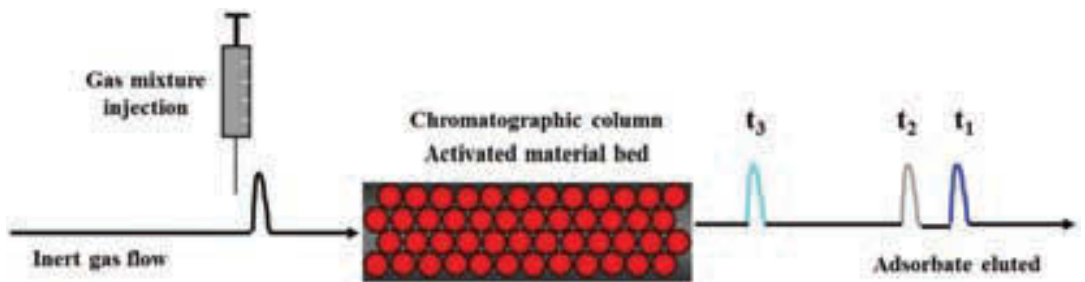

Figure 4. Scheme of the Inverse Gas Chromatography method.

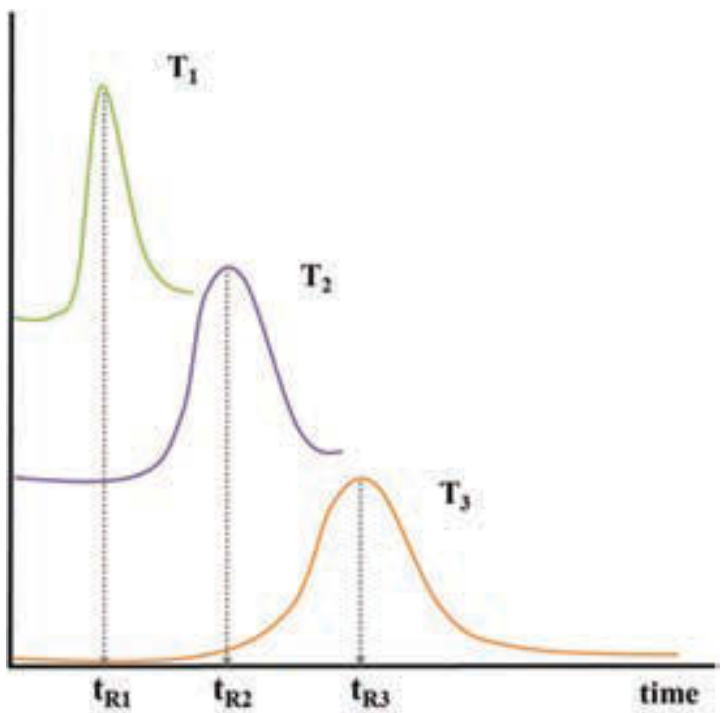

Figure 5. Effect of temperature variation on the shape and position of the peak of a chromatogram.

After the introduction of the probe molecules into the system, adsorptiondesorption processes take place and are represented in the chromatogram by means of peaks (Figure 5) [15]. Each peak corresponds to an adsorbate eluted from the column at a certain time, known as retention time $\left(t_{\mathrm{R}}\right)$, and at a different temperature (Figure 5 , where $\mathrm{T}_{1}>\mathrm{T}_{2}>\mathrm{T}_{3}$ ).

The independence of the retention time with the volume of adsorbate injected ensures that the adsorption process takes place in the region where Henry's Law is satisfied (zero coverage surface). This region involves chromatographic peaks being symmetric or with a small asymmetry, regardless of the amount injected. Then, the equilibrium constant of the adsorption process or Henry constant $\mathrm{c}$ is defined as the net retention volume per unit area $\left(\mathrm{V}_{\mathrm{s}}\right)$, which can be determined by the equation (3): 


$$
V_{s}=\frac{V_{R}}{S_{B E T}} m
$$

where $S_{B E T}$ is the specific surface area of the material, $m$ is the dry weight of the adsorbent sample inside the column, and $V_{R}$ is the retention volume, which is determined from the retention time and flow of the carrier gas $[16,17]$. The adsorption heat, $\Delta \mathrm{H}_{\text {ads }}$, can be calculated by applying the Clausius-Clapeyron equation (4) to this region.

$$
\Delta H_{a d s}=-R\left(\frac{\partial \ln V_{s}}{\partial\left(\frac{1}{T}\right)}\right)_{N}
$$

This equation can be linearized to obtain (5) from which the graphical representation calculates $\Delta \mathrm{H}_{\text {ads }}$ more easily.

$$
\ln V_{s}=-\frac{\Delta H_{a d s}}{R T}+C
$$

Finally, with knowledge of the values of the Henry constants for each adsorbate, the partition coefficient can also be estimated, Equation (6) shows $\alpha_{x / y}$ as a measure of the degree of separation expected for a binary mixture.

$$
\ln \alpha_{x / y}=\frac{\left(\Delta H_{a d s 1}-\Delta H_{a d s 2}\right)}{R T}
$$

\section{Strategies to enhance adsorption processes}

Different methodologies can be applied to modify the adsorption properties of MOFs and zeolites. For example, post-synthetic modification (PSM) of the structure of porous materials is a widely used technique for the improvement of the adsorption capacity and selectivity of different gases. It should be noted that adsorption is not only important for gas adsorption and separation processes but is also essential for many other applications, such as catalysis, water purification, etc.

In the field of zeolites, it is important to highlight a process known as ion exchange, which has been widely used for many years. This process refers to the exchange of ions between a liquid and a solid phase [18]. As is well known, the lattice of zeolites is built by $\mathrm{SiO}_{4}$ and $\mathrm{AlO}_{4}$ tetrahedra. Since aluminium is trivalent, the lattice carries a negative electric charge. This charge must be balanced by cations, which can be exchanged for other cations from a liquid phase as they diffuse along the channels of the zeolite [19]. 


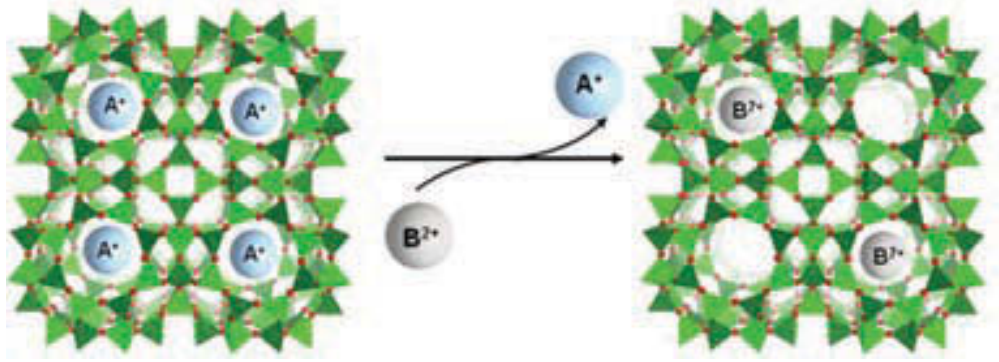

Figure 6. Example of ion exchange process in LTA zeolite.

Thus, when a zeolite containing a generic cation $\mathrm{A}^{+}$is immersed in a solution containing $\mathrm{B}^{+}$, a diffusion process is established in which $\mathrm{B}^{+}$diffuses into the porous structure and replaces $\mathrm{A}^{+}$, which diffuses out from the zeolite crystal (Figure 6).

In this context, the incorporation of different cations in the structure of some zeolites can improve the adsorption capacity of different gases [20]. For example, the ion exchange method has been researched for the purposes of eliminating sulphur compounds $\left(\mathrm{H}_{2} \mathrm{~S}\right)$ from diesel and gasoline. Hoguet et al. synthesized different ion exchanged zeolites, namely $\mathrm{Nd}-$ $\mathrm{NaY}, \mathrm{La}-\mathrm{NaY}$ and $\mathrm{Ce}-\mathrm{NaY}$, through the liquid ion exchange method from the commercial precursor zeolite $\mathrm{NaY}$. The $\mathrm{La}-\mathrm{NaY}$ and $\mathrm{Ce}-\mathrm{NaY}$ zeolites improved the $\mathrm{H}_{2} \mathrm{~S}$ adsorption capacity significantly compared to the commercial zeolite [21].

In addition, in recent decades post-synthesis treatments of parent zeolites have also been studied in order to alter the $\mathrm{Si} / \mathrm{Al}$ ratio $[22,23]$. The framework $\mathrm{Si} / \mathrm{Al}$ atomic ratio of zeolites is an important parameter that exerts a strong influence on properties such as the maximum ion exchange capacity, thermal and hydrothermal stability, hydrophobicity, and acidic properties. A variation in the $\mathrm{Si} / \mathrm{Al}$ ratio can also create a certain extra porosity due to the presence of defect sites in the zeolite framework upon post-treatment [24]. For instance, silicon extraction through treatment in an aqueous alkaline solution, known as desilication, has proven to create extra porosity in different types of zeolites [25-27]. Furthermore, the selective removal of aluminium from the zeolite framework or dealumination, is generally achieved through steam treatment at relatively high temperatures by means of acid leaching or alkaline treatments [28-30].

However, PSM in zeolites has not been very widely used due to the limitations of these materials, such as the rigidity of their porous skeleton or the difficulty in functionalizing the porous surface. Nevertheless, a few 


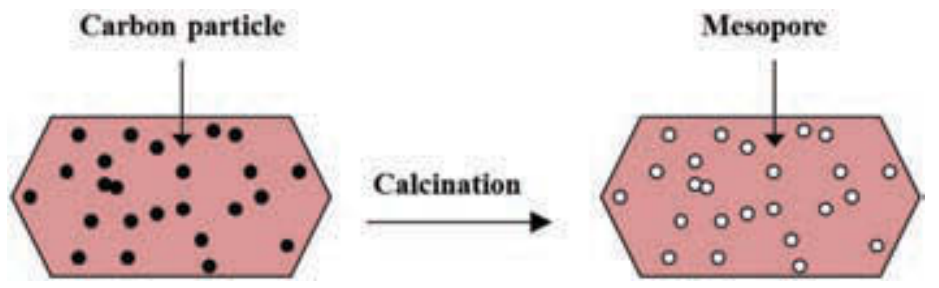

Figure 7. Synthesis of hierarchical zeolite by carbon nanoparticles.

examples of zeolite surface modifications have been reported and will be described below. For this reason, other methods have been developed in order to improve the porosity and adsorption properties of zeolites. In this sense, over the last decade studies regarding hierarchical zeolites have increased dramatically [31-33]. The term hierarchical zeolites, refers to zeolites featuring at least one additional level of porosity in addition to their intrinsic micropore system [34]. Nevertheless, in practice, the expression hierarchical zeolites, is nearly always used to refer to zeolites containing mesopores (pores with diameters in the range of $2-50 \mathrm{~nm}$ ).

In this context, the most commonly used synthesis method for increasing porosity in zeolites is by templates. The templating route involves the use of different materials such as carbon nanoparticles [35], carbon aerogels [36], micelles [37], surfactants [38], polymers [39], etc. Carbonaceous materials were the first systems studied as templates due to their properties including chemical inertness, structural diversity and ease of removal by combustion [40]. In this case, the hierarchical zeolites are produced when the growing zeolite crystals encapsulate the carbon matrix during synthesis, featuring a zeolite embedded with carbon material after the zeolite crystallization. Afterwards, the carbon matrix is removed by combustion, resulting in a material with mesopores (Figure 7) [32].

On the other hand, the enormous versatility of MOFs has allowed the development of different methodologies with the intention of modifying their structures and, consequently, improving their adsorption properties. The ability to modify the physical environment of the pores and cavities within MOFs would allow the tuning of interactions with guest species. In this sense, two different strategies have been employed to achieve MOF functionalization.

The first is a pre-synthetic methodology. This strategy involves the use of a functionalized ligand [41,42] or metalloligands [43] as the organic linker. For instance, the isoreticular metal-organic framework (IRMOF) series of materials described by Yaghi et al. were synthesized with many different 
functional groups (amine, nitro, chlorine, bromine, etc.) [44]. However, this methodology presents some limitations. For example, under solvothermal conditions, the ligands cannot contain thermally labile groups. For this reason, the range of chemical functionality found in IRMOFs is rather limited. Functional groups such as alcohols, aldehydes, carboxylic acids, nitriles, azides, alkylamines, thiols, phosphines, and many others are absent from the list of ligands that have been used.

Fortunately, PSM can overcome the limitations present in prefunctionalized methods. In this sense, modified materials with a wide variety of functional groups can be obtained as long as the original MOFs are sufficiently robust and porous allowing transformations in a final step. The materials are thus able to conserve their structural integrity. Post-synthetic modification of MOFs can be also described as the chemical derivatization of MOFs after their formation [45]. The advantages offered by the PSM approach to functionalizing MOFs are the following: $i$ ) it is possible to include a more diverse range of functional groups, ii) purification and isolation of modified products is easy because the chemical functionalization is performed directly on crystalline solids, iii) the same MOF structure can be functionalized with different groups, thereby yielding a high number of topologically identical but functionally diverse MOFs, iv) control over both the type of functional group and the degree of modification allows for the optimization and improvement of MOF adsorption properties.

In the last decade, many different PSM strategies related to MOFs have been developed. Regarding gas adsorption, modification of secondary building units (SBUs) [46], ion exchange [47] and formation of defects [48] have been the most widely studied.

\section{Modification of secondary building units (SBUs)}

As we have seen in previous chapters, secondary building units are the inorganic parts of a MOF. There are many MOFs containing labile ligands, which are often coordinated solvent molecules, attached to the secondarybuilding units. These ligands can be removed by heating to generate a porous material with open coordination sites, thus allowing for the substitution of these labile ligands with another ligand, often leading to enhanced adsorption properties [49-51].

For example, post-synthetic modifications of HKUST-1 $\left[\mathrm{Cu}_{3}(\mathrm{btc})_{2}\left(\mathrm{H}_{2} \mathrm{O}\right)_{3}\right]$ (btc = benzene-1,3,5-tricarboxylate) have been widely studied due to the easy generation of unsaturated metal sites in its structure. HKUST-1 


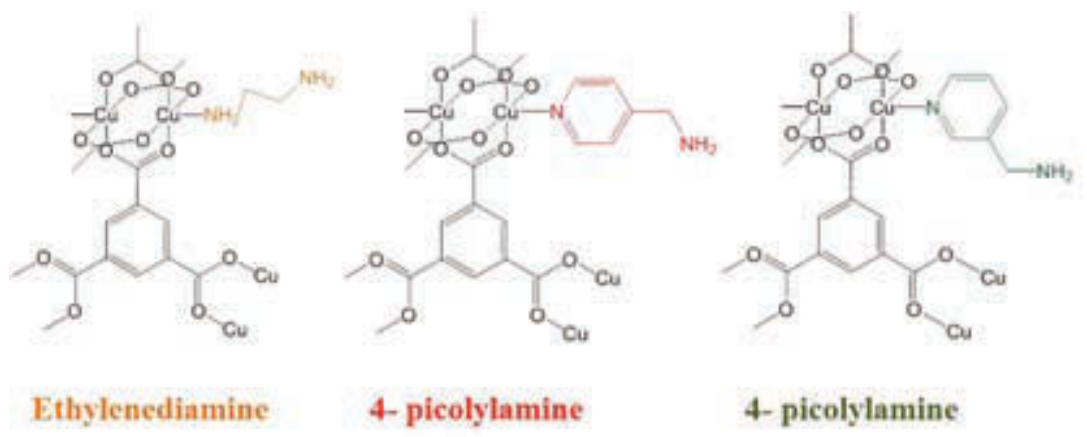

Figure 8. Scheme of functionalization of HKUST-1 with ethylenediamine, 4-picolylamine and 3-picolylamine.

contains coordinated water molecules at $\mathrm{Cu}$ (II) centres which can be easily removed by heating and consequently, replaced by another ligand. In this sense, Navarro et al. have carried out the functionalization of HKUST-1 with different bifunctional amines (Figure 8). It is interesting to note that the material modified with 3-picolylamine significantly improved $\mathrm{CO}_{2}$ adsorption compared to pristine HKUST-1 [52].

\section{Formation of defects}

Defects can be defined as structural disorders and heterogeneities that break the periodic arrangement of atoms. In this context, the structure of MOFs contains a considerable density of structural irregularities or defects. These inherent defects are formed during crystal growth in the form of missing metal nodes or linkers (either the entire molecule or as a result of stacking faults or dislocations) [48].

Nevertheless, in recent years, many studies have demonstrated that the presence of defects in MOFs produces an improvement in adsorption and catalytic properties [53-57]. Therefore, the possibility of controlling the form, size, and number of defects through post-synthetic modification is very interesting and several methodologies have been developed to this end. For instance, acid/base post-synthetic treatment has been proven to be an efficient strategy for introducing defects into pre-formed MOFs [58]. Recently, thermal treatment of $\left[\mathrm{Zn}_{4} \mathrm{O}(\mathrm{BDC})_{3}\right](\mathrm{BDC}=1,4$-benzene dicarboxylate) MOF- 5 has been studied. This study reveals that temperatures below the decomposition point of the material but above the conventional solvent evacuation temperature induce the partial decomposition of the 
carboxylate ligands, generating a local defective vacancy structure. The vacancy defect led to an improvement in $\mathrm{CO}_{2}$ adsorption capacity due to the presence of active sites at the framework linker and the unsaturated metal sites [59].

\section{Ion exchange}

It is possible to carry out cation exchange in MOFs in a similar way to zeolites. Although there are not many examples of ionic MOFs [6o-62], ionic sites can be introduced to neutral frameworks by means of postsynthetic functionalization treatments, including the removal of some of the linkers, among others [47]. In this context, cation exchange in the material $\mathrm{K}\left[\mathrm{Ni}_{8}(\mathrm{OH})_{6}\left(\mathrm{H}_{2} \mathrm{O}\right)_{2}(\mathrm{BDP})_{5.5}\right](\mathrm{BDP}=1,4$-bis(pyrazol-4-yl $)$ benzene $)$ has recently been studied. In this study, extra-framework $\mathrm{Ba}(\mathrm{II})$ ions were introduced into the porous structure through an exchange process with $\mathrm{K}(\mathrm{I})$ cations. It was found that the post-synthetically modified MOF material enhanced $\mathrm{SO}_{2}$ adsorptive properties [63].

\section{Gas adsorption on zeolites and metal-organic frameworks}

As already mentioned, adsorption capacity is one of the main factors that determine the possible application of a porous material. In this sense, different gas adsorption capabilities in MOFs and zeolites have been tested, mainly focused on specific potential applications related to energy, environment remediation, gas separation, and sensors, among the most important ones. The following discussion is divided into three sections with the objective of highlighting the gas adsorptive properties of zeolites and MOFs according to their applications: energy, $\left(\mathrm{H}_{2}\right.$ and $\left.\mathrm{CH}_{4}\right)$, environmental remediation $\left(\mathrm{CO}_{2}, \mathrm{NOx}\right.$ and $\left.\mathrm{SO}_{2}\right)$, and other applications for gas adsorption.

\subsection{Applications in energy}

\section{Hydrogen}

In the last few decades, a demand for clean and efficient energy sources has grown due to the decreasing availability of fossil fuel resources. The chemistry community has focused research on the exploration of alternative sources of clean energy, hydrogen being a promising means for these purposes [64]. 
Hydrogen adsorption is governed by framework topologies and exchangeable extraframework cations in zeolites. For example, Langmi et al. reported the hydrogen adsorption capacities in zeolites A, X, Y and RHO, and diverse results were obtained depending on the adsorption temperature, pore size and metal ions exchanged on each zeolite [65]. In another work Na-LEV, H-OFF, Na-MAZ and Li-ABW zeolites were examined with similar concluding remarks referred to the large volume of micropore cations, as a key factor for enhancing hydrogen uptake capacities [66].

On the other hand, MOFs with extremely high surfaces areas (up to $7100 \mathrm{~m}^{2} \mathrm{~g}^{-1}$ ) [67] have been widely researched for hydrogen adsorption. However, the relatively low gravimetric and volumetric densities of hydrogen adsorbed on MOFs under ambient conditions remains a challenge to be overcome. This is especially so in view of the US Department of Energy (DOE) goals for 2020 [68], by which hydrogen on-board vehicle storage systems should achieve densities of $5.5 \mathrm{wt} . \%$ and $40 \mathrm{~g} \mathrm{l}^{-1}$.

Several strategies have been adopted to enhance hydrogen adsorptive properties on MOFs [69]. These are mainly focused on improving the interactions between adsorbed hydrogen molecules and the adsorbent by means of higher surface areas and porosities (achievable by catenation and interpenetration), interactions with metal centres (open metal sites, extra-framework metal species, etc.) and with pore walls and/or ligands (van der Waals, functional groups, etc.).

Different authors have studied and reviewed works on MOFs for hydrogen storage applications [70-72], underlining the features needed in these materials for improved hydrogen adsorption at room temperatures. It is worth mentioning materials like MOF-5 $\left(\mathrm{Zn}_{4} \mathrm{O}(\mathrm{BDC})_{3}\right)$ [73], on which Yaghi et al. studied the rotational transitions of hydrogen molecules adsorbed on binding sites by inelastic neutron scattering microscopy, or the higher hydrogen uptake showed by the isoreticular IRMOF- 6 and -8. In another work, the same authors followed the study of the isoreticular series from which it was assumed that the stronger influence of catenation in hydrogen adsorption behaviour compared with the introduction of functional groups like $-\mathrm{Br}$, $-\mathrm{NH}_{2}$ and $-\mathrm{C}_{2} \mathrm{H}_{4}$ and additionally, a substantial hydrogen uptake was noted when open metal sites, like in HKUST-1 and MOF-74 [74], were presented.

Dincă et al. studied the interactions of metal cations $\mathrm{Li}^{+}, \mathrm{Cu}^{+}, \mathrm{Fe}^{2+}, \mathrm{Co}^{2+}$, $\mathrm{Ni}^{2+}, \mathrm{Cu}^{2+}$ and $\mathrm{Zn}^{2+}$ in exchanged $\mathrm{Mn}_{3}\left[\left(\mathrm{Mn}_{4} \mathrm{Cl}\right)_{3}(\mathrm{BTT})_{8}\left(\mathrm{CH}_{3} \mathrm{OH}\right)_{10}\right]_{2}(\mathrm{BTT}=$ 1,3,5-tris(tetrazol-5-yl)benzene) MOF with adsorbed hydrogen molecules $[75,76]$. The same approach was taken by Schroder et al. [77], who used $\mathrm{Li}^{+}$as a counter-ion in the framework to enhance the adsorptive properties 
of the indium-containing MOF studied. Hydrogen adsorption on a series of $\mathrm{Cu}$ (II) tetracarboxylate MOFs (namely NOTT-10o-109) was studied by Schroder et al., supporting the central role of exposed metal centers, pore size and ligands functionalities in the adsorption process [74].

In contrast, a study on a rare earth metal MOF by powder neutron diffraction revealed the preferred interactions of hydrogen molecules with the pore walls rather that with the open metal sites [75]. Chen and colleagues, studied the hydrogen adsorption properties in an interpenetrated, framework, $\mathrm{Zn}(\mathrm{NDC})\left(4,4^{\prime} \mathrm{Bpe}\right)_{0.5}(\mathrm{NDC}=2,6$-naphthalenedicarboxylate, Bpe = 4,4'-trans-bis(4-pyridyl)-ethylene), showing features of dynamic MOFs hydrogen adsorption at room temperature and high pressures [79].

Some examples of zeolites and MOFs are summarized in Table 1, highlighting their adsorption capacities and measurement conditions [77-83].

\section{Methane}

Methane is considered an alternative source of transport fuel, since there are large natural reserves and it has a high research octane number $(\mathrm{RON}=107)$ due to its low carbon content. In addition, the current compressed natural gas technologies require the use of containers at high pressure and extreme safety conditions. Therefore, natural gas adsorption technologies are a highly desirable -and also challenging- choice. For practical uses in transport, it is important to clearly differentiate the terms used for methane, the deliverable capacity being the most important one, compared to the adsorption capacity. The former is related to the working capacity of the adsorbent releasing methane between high pressure to 5 bar from the adsorbent container [88,89].

The Advanced Research Projects Agency-Energy (ARPA-E) of the US Department of Energy (DOE) has set the new target for methane volumetric storage capacity to $350 \mathrm{~cm}^{3}$ (STP) $\mathrm{cm}^{-3}$, and for gravimetric capacity to $0.5 \mathrm{~g}$ $\left(\mathrm{CH}_{4}\right) \mathrm{g}^{-1}$, at ambient temperature, for automobile ANG (Adsorbed Natural Gas) applications [9o].

Over zeolites, due to the ionic nature of the pore surface and their hydrophillicity, methane adsorption is not especially favoured [91,92]. However, this handicap has been overcome and different zeolites have been tested for methane storage [93], and even a methane storage system has been patented using zeolites as adsorbents [94]. Similarly, the combination of MOFs and zeolites in a device named zeolite adsorbent-MOF layered nanovalve led to the improvement of their $\mathrm{CH}_{4}$ storage capacities. For example, an Al-MOF/zeolite $5 \mathrm{~A}$ composite nanovalve can store $33.6 \mathrm{l}$ (STP) $\mathrm{l}^{-1}$ at pressures $<1$ bar [95]. 


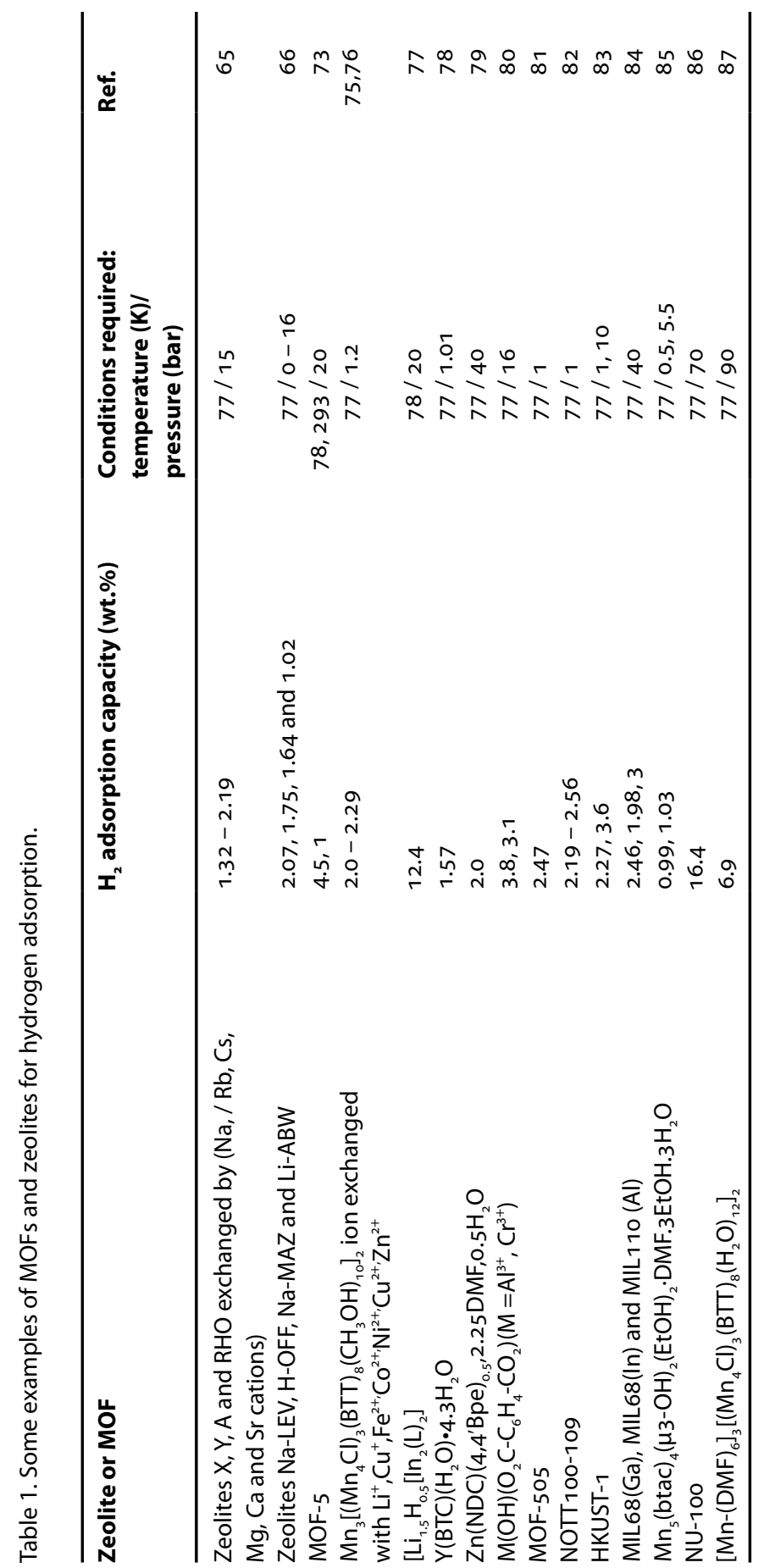


Table 2. Some examples of methane storage capacities and conditions of adsorption in MOFs and zeolites.

\begin{tabular}{|c|c|c|c|}
\hline Zeolite or MOF & $\begin{array}{l}\mathrm{CH}_{4} \text { volumetric } \\
\text { uptake }\left(\mathrm{cm}^{3} \mathrm{~cm}^{-3}\right) / \\
\text { working capacity } \\
\left(\mathrm{cm}^{3} \mathrm{~cm}^{-3}\right)\end{array}$ & $\begin{array}{l}\text { Conditions required: } \\
\text { temperature }(\mathrm{K}) / \\
\text { pressure (bar) }\end{array}$ & Ref. \\
\hline $5 \mathrm{~A}$ & $104 /-$ & $298 / 35$ & 88 \\
\hline $13 X$ & $106 /-$ & $298 / 35$ & 93 \\
\hline CaX zeolite & $150 /-$ & $276 / 9$ & 94 \\
\hline HKUST-1 & $225 / 200$ & $298 / 35$ & 101 \\
\hline $\mathrm{Co}(\mathrm{BDP})$ & $-/ 197$ & $298 / 65$ & 102 \\
\hline NOTT-108a & $247 / 186$ & $298 / 65$ & 99 \\
\hline NOTT-101a & $237 / 188$ & $298 / 65$ & 105 \\
\hline$\left[\mathrm{Zn}_{3}(\mathrm{pypz})_{3}(\mathrm{btc})\right] \cdot$ guest & 263 & $298 / 65$ & 106 \\
\hline UTSA-20 $\left[\mathrm{Cu}_{3}(\mathrm{BHB})\right]$ & 195 & $300 / 35$ & 107 \\
\hline UTSA-76a & $260 / 200$ & $298 / 65$ & 97 \\
\hline UTSA-88a & $248 / 185$ & $298 / 65$ & 111 \\
\hline MOF-74-Ni & $251 / 129$ & $298 / 65$ & 109 \\
\hline $\mathrm{PCN}-14$ & $230 / 157$ & $298 / 65$ & 109 \\
\hline $\mathrm{NU}-125$ & $232 / 183$ & $298 / 65$ & 103 \\
\hline $\mathrm{NU}-111$ & $206 / 179$ & $298 / 65$ & 109 \\
\hline MOF-905 & $228 / 203$ & $298 / 80$ & 104 \\
\hline MOF-950 & $209 / 174$ & $298 / 80$ & 104 \\
\hline ZJNU-30a & $179.3 / 151$ & $298 / 65$ & 112 \\
\hline ZJNU-31a & $137.7 / 115$ & $298 / 65$ & 112 \\
\hline ZJNU-53 & $241 / 190$ & $298 / 65$ & 113 \\
\hline NJU-Baiзо & $186 /-$ & $298 / 65$ & 114 \\
\hline NJU-Bai31 & $158 /-$ & $298 / 65$ & 114 \\
\hline
\end{tabular}

Taking into consideration the high surface areas and tunabilities of pore surface in MOFs, they are the candidates of choice compared to other porous adsorbents such as zeolites or porous carbons. In MOFs, the study of adsorption and release capacity of methane has allowed to identify two favourable binding interactions of methane: i) the Coulomb interactions of methane with open metal sites, and ii) the van der Waals interactions with small cages/channels [96]. However, more recently, new findings on improved methane adsorption have been found in MOFs with nitrogen-containing $[97,98]$ or fluorinated $[99,100]$ ligands.

Some benchmark materials for methane storage, like HKUST-1 [101], Co(BDP) [102], UTSA-76a [97] and Al-soc-MOF-1 [103], with working capacities close to DOE target values (Table 2) have been reported. Recently, other MOFs with also high volumetric storage capacities have been evaluated, such as 
MOF-905 and MOF-950 (with working capacities of 203 and $174 \mathrm{~cm}^{3}$ (STP) $\mathrm{cm}^{-3}$, respectively, at $298 \mathrm{~K}$ and 8o bar) [104], or NOTT-108a [99] and NOTT-101a [105].

It is worth noting a very recent paper where $\left[\mathrm{Zn}_{3}(\mathrm{pypz})_{3}(\mathrm{btc})\right] \cdot$ guest.MOF $(\mathrm{MAF}-38)(\mathrm{pypz}=4-(1 \mathrm{H}-$ pyrazol-4-yl $)$ pyridine $)$ affords a high methane uptake $(263 \mathrm{v} / \mathrm{v}$ at $298 \mathrm{~K}$ and 65 bar $)$ and adsorption enthalpies $\left(21.6 \mathrm{~kJ} \mathrm{~mol}^{-1}\right)$ close to the highest storage MOFs available, like HKUST-1, with open metal sites as the preferred binding sites for methane adsorption in the framework [106]. Another good example of high methane uptake at room temperature is UTSA-20 that reaches a storage density of $0.22 \mathrm{~g} \mathrm{~cm}^{3}$ resulted the highest density of open copper sites in a MOF [107]. Other authors have illustrated the methane storage capacity of other benchmark MOFs, the possibilities to have improved capacities in the future MOFs, and the influence of packing density of MOFs on experimental working capacities [101,108-110]. Some reviews also highlight the methane storage capacities of adsorbent or porous materials like MOFs, COFs (covalent organic frameworks), zeolites and carbons [100]. In Table 2, a few examples of zeolites and MOFs are summarized for a better comparison of their capacities [111-114].

\subsection{Environmental remediation}

\section{Carbon dioxide}

In recent decades, our dependence on fossil fuels for energy generation has led to an increase in the $\mathrm{CO}_{2}$ emissions released to the atmosphere. As a consequence, the temperature of the Earth surface has increased by about $0.85^{\circ} \mathrm{C}$ since pre-industrial levels. The temperature is expected to increase by the end of the 21 st century by $4{ }^{\circ} \mathrm{C}$ if greenhouse gas emissions are not reduced. According to a report published by the Intergovernmental Panel on Climate Change (ICPP) [115], in order to reduce the adverse effects of climate change, by 2100 the Earth's surface temperature must not increase beyond a threshold of $2{ }^{\circ} \mathrm{C}$. To achieve this, greenhouse gas emissions must be reduced by between 40 and $70 \%$ globally between 2010 and 2050 , and be reduced to zero by 2100 . With this in mind, many zeolites and metalorganic frameworks have been studied for their ability to capture $\mathrm{CO}_{2}$.

In the case of zeolites, a robust nature, coupled with their low cost and well-developed structural chemistry, makes these materials an attractive target for use in $\mathrm{CO}_{2}$ capture applications. Moreover, the presence of cations such as $\mathrm{Na}(\mathrm{I}), \mathrm{Ca}(\mathrm{II})$, or $\mathrm{Li}(\mathrm{I})$ influences the adsorption capacity of $\mathrm{CO}_{2}$ due to the interaction between alkali ions and $\mathrm{CO}_{2}$ molecules [116]. The high quadrupole moment of $\mathrm{CO}_{2}\left(14.2910^{-40} \mathrm{C} \mathrm{m}^{2}\right)$ interacts strongly with the electric 
Table 3. Some examples of carbon dioxide storage capacities and conditions of adsorption in zeolites.

\begin{tabular}{lclr}
\hline Zeolite & $\begin{array}{l}\mathrm{CO}_{2} \text { adsorption } \\
\text { capacity (wt\%) }\end{array}$ & $\begin{array}{l}\text { Conditions required: } \\
\text { temperature (K) / pressure (bar) }\end{array}$ & \multicolumn{1}{l}{ Ref. } \\
\hline 13X & $4,20.5$ & $393 /-, 298 / 1.01$ & 124,118 \\
$13 \mathrm{X}-\mathrm{MEA}$ & 14 & $393 /-$ & 124 \\
$\mathrm{NaX}$ & 25.1 & $305 / 1.01$ & 119 \\
$\mathrm{NaY}$ & 24.2 & $305 / 1.01$ & 119 \\
$\mathrm{ZSM}-5$ & 1.3 & $313 / 0.1$ & 120 \\
$5 \mathrm{~A}$ & 23.3 & $298 / 14$ & 121 \\
\hline
\end{tabular}

field created by the structural cations of zeolites, increasing their adsorption capacity [117]. Because of this, zeolites have shown promising results with regard to the separation of $\mathrm{CO}_{2}$ from gas streams. In this sense, there are many studies concerning the $\mathrm{CO}_{2}$ adsorption capacity of both natural and synthetic zeolites. Table 3 summarizes some different zeolites that have been studied for $\mathrm{CO}_{2}$ adsorption and separation from gas mixtures [118].

However, $\mathrm{CO}_{2}$ adsorption capacity in zeolite materials decreases significantly at high temperatures and/or by the moisture present in flue gases [122]. Nevertheless, it is possible to avoid these limitations by means of post-synthetic modification of zeolites. For example, Zhang et al. showed a cation exchange strategy for chabazite $(\mathrm{CHA})$ zeolites $(\mathrm{Si} / \mathrm{Al}<2.5)$ with several ions, including $\mathrm{Li}(\mathrm{II}), \mathrm{Na}(\mathrm{I})$ and $\mathrm{Mg}(\mathrm{II})$, among others. In the study, the Na-CHA and Ca-CHA materials presented advantages in $\mathrm{CO}_{2}$ separation at high temperatures [123]. Furthermore, it is important to highlight PSM use through the incorporation of amine groups. In this sense, Jadhav et al. studied the modified zeolite ${ }_{13} \mathrm{X}$ via monoethanol amine (MEA) impregnation to improve its $\mathrm{CO}_{2}$ adsorption capacity (Table 3). The aminated zeolites showed a higher capacity than the pristine zeolites at $120^{\circ} \mathrm{C}[124]$. Su et al reported a similar conclusion. In this case, the Y-type zeolite was functionalized with tetraethylenepentamine [125].

On the other hand, MOFs are also excellent candidates for $\mathrm{CO}_{2}$ adsorption due to their remarkably high surface area, controllable pore structures, and tunable pore surface properties. MOF- 5 was the first MOF reported for $\mathrm{CO}_{2}$ capture [126]. Since then, the amount of studies published has increased dramatically. Table 4 summarizes the $\mathrm{CO}_{2}$ adsorption capacity of the most common MOFs for $\mathrm{CO}_{2}$ capture [127-130]. It is interesting to note that MOF210 presents an excellent $\mathrm{CO}_{2}$ adsorption capacity due to the ultrahigh porosity of this MOF (Table 4) [131]. 
Table 4. Some examples of carbon dioxide storage capacities and conditions of adsorption in MOFs.

\begin{tabular}{llll}
\hline MOF & $\begin{array}{l}\text { CO } \text { adsorption } \\
\text { capacity (wt.\%) }\end{array}$ & $\begin{array}{l}\text { Conditions required: } \\
\text { temperature (K)/ } \\
\text { pressure (bar) }\end{array}$ & Ref. \\
\hline MOF-5 & 50 & $298 / 14$ & 121 \\
MOF-177 & 39.7 & $298 / 1.01$ & 121 \\
MOF-74-Ni & 23.9 & $298 / 1$ & 128 \\
MOF-74-Mg & 27.5 & $298 / 1$ & 129 \\
ED-MOF-74-Mg & 38.2 & $298 / 1$ & 132 \\
MOF-74-Co & 24.9 & $298 / 1$ & 130 \\
MOF-74-Zn & 19.8 & $298 / 1$ & 128 \\
HKUST-1 & 19.8 & $298 / 1$ & 127 \\
MOF-210 & 240 & $298 / 50$ & 131 \\
\hline
\end{tabular}

As discussed earlier, PSM in metal-organic frameworks is a very useful tool for improving $\mathrm{CO}_{2}$ adsorption capacity due to the versatility of these materials. As with zeolites, the presence of amino groups in MOFs enhances $\mathrm{CO}_{2}$ adsorption. However, it is interesting to note that the incorporation of amines into MOFs is not achieved through the impregnation method as it is in zeolites. As it was mentioned in the previous section, in MOF materials it is possible to functionalize the coordinatively unsaturated metal sites. For example, MOF-74-Mg has been widely studied in $\mathrm{CO}_{2}$ adsorption and their functionalization with ethylenediamine (ED) improves significantly its adsorption capacity [132].

\section{Toxic gases}

In addition to $\mathrm{CO}_{2}$, fossil fuel combustion also emits toxic gases such as $\mathrm{NO}_{\mathrm{x}}$ and $\mathrm{SO}_{\mathrm{x}}$ into the atmosphere. Among various sulphur and nitrogen oxide species, $\mathrm{NO}_{2}, \mathrm{NO}$, and $\mathrm{SO}_{2}$ are considered the most toxic and harmful gases. These acidic gases generate serious environmental problems such as photochemical smog and acid rain.

In the field of zeolites, adsorptive removal of $\mathrm{NO}$ and $\mathrm{NO}_{2}$ has been studied using zeolites at relatively low temperatures. These gases can be adsorbed through the reversible binding of nitrogen with framework cations. In this case, the gas is physically adsorbed and can be easily removed by slightly decreasing the pressure. In addition, NO can be chemically adsorbed by an irreversible bond to the surface, forming nitrosyl complexes. Notably, this kind of bonding of NO provides the opportunity for its storage [133]. 
Zeolites have also been tested for $\mathrm{SO}_{2}$ capture. The $\mathrm{SO}_{2}$ adsorption process in zeolites may be favoured due to the strong ion-dipole interaction between $\mathrm{SO}_{2}$ molecules and the cations of the zeolite. However, due to the variety of bonding modes of $\mathrm{SO}_{2}$ molecules, they can also interact with the Lewis basic sites of zeolites (the bridging oxygen atom in $\mathrm{Si}-\mathrm{O}-\mathrm{Al}$ ). Oxygen can form a bond with the sulphur atom through donor-acceptor interaction. In addition, in some zeolites $\mathrm{SO}_{2}$ is chemisorbed and a formation of $\mathrm{HSO}_{3}^{-}$or $\mathrm{SO}_{4}^{2-}$ is observed [134]. Table 5 shows $\mathrm{SO}_{2}$ and NO adsorption capacity for ${ }_{13} \mathrm{X}$ and $5 \mathrm{~A}$ zeolites.

On the other hand, the presence of open coordinatively unsaturated metal centres in MOFs opens the way to functionalization with basic groups or to incorporation of cations with affinity for $\mathrm{SO}_{2}$ and $\mathrm{NO}_{\mathrm{x}}$ adsorbates. Moreover, the adsorption process in MOFs can be carried out by coordination bonds, acid-base/electrostatic interactions, H-bonding formation, etc. [135] Many articles discussing this process have been published in the last decade. Table 5 shows the adsorption capacity of these toxic gases in different MOFs [136-143]. In addition, other articles have

Table 5. Some examples of sulphur dioxide, nitrogen oxide and nitrogen dioxide storage capacities and conditions of adsorption in zeolites and MOFs.

\begin{tabular}{lllll}
\hline Gas & $\begin{array}{l}\text { Zeolite or } \\
\text { MOF }\end{array}$ & $\begin{array}{l}\text { Adsorption } \\
\text { capacity } \\
\left(\mathbf{m m o l ~ g}^{-1}\right)\end{array}$ & $\begin{array}{l}\text { Conditions required: } \\
\text { temperature (K) / pressure } \\
\text { (bar) or [concentration] }\end{array}$ & Ref. \\
\hline $\mathrm{SO}_{2}$ & $13 \mathrm{X}$ & 2.5 & $323 / 0.5$ & 136 \\
& $5 \mathrm{~A}$ & 1.5 & $323 / 0.5$ & 136 \\
& MOF-5 & 1 & $298 /[1 \%]$ & 137 \\
& MOF-177 & $<1$ & $298 /[1 \%]$ & 137 \\
& HKUST-1/Ba & 2.4 & $473 /[50 \mathrm{ppm}]$ & 138 \\
& IRMOF-3 & 6 & $298 /[1 \%]$ & 137 \\
& MOF-74-Zn & 3 & $298 /[1 \%]$ & 137 \\
\hline NO & 13X & 0.1 & $323 / 0.5$ & 136 \\
& 5A & 0.1 & $323 / 0.5$ & 136 \\
& MOF-74-Ni & 7 & $298 / 1$ & 139 \\
& HKUST-1 & 3 & $298 / 1$ & 140 \\
& MIL-88A & 7.1 & $303 / 1$ & 141 \\
\hline NO $_{2}$ & UiO-66 & 1.1 & $298 /[1000 \mathrm{ppm}]$ & 142 \\
& UiO-67 & 1.7 & $298 /[1000 \mathrm{ppm}]$ & 143 \\
& HKUST-1 & 1.7 & $298 /[1000 \mathrm{ppm}]$ & 143 \\
\hline
\end{tabular}

${ }^{a}$ gas toxic concentration in gas mixture 
been published for MOFs concerning other toxic gases adsorption, such as chemical warfare agents $[144,145]$.

\subsection{Other applications for gas adsorption}

Adsorption of other gases on zeolites and MOFs, such as oxygen, noble gases, water vapour and volatile organic compounds (VOCs), has been studied with interesting results. Some examples of adsorption of the abovementioned gases, is described below.

Since oxygen needs to be stored in high-pressure containers for medical, industrial and aerospace applications, its adsorptive properties on different materials like, zeolites, porous carbons and MOFs, have been evaluated. For instance, zeolites have been widely used for adsorption and enrichment of $\mathrm{O}_{2}$ from air, obtaining concentrations of up to $99.5 \%$ pure $\mathrm{O}_{2}$ using AgLiLSX zeolite [146]. Other zeolites used for similar purposes are zeolite $5 \mathrm{~A}$ [147] and LiLSX zeolite [148,149]. However, oxygen adsorption in MOFs has been less explored. An excellent review has been published by DeCoste et al. [150] where a computational screening of 10,000 MOFs for oxygen storage is presented. Benchmark MOFs, such as HKUST-1, NU-125 and UiO-66, are experimentally tested and their structural features and properties that can stimulate the $\mathrm{O}_{2}$ adsorption are also studied. In another work, MOF Al-soc-MOF-1 showed an absolute gravimetric $\mathrm{O}_{2}$ uptake of $29 \mathrm{mmol} \mathrm{g}^{-1}$, being among the highest uptakes reported so far [103]. Additionally, other MOFs have been reported for the adsorption and storage of oxygen, highlighting the framework properties that stimulate the $\mathrm{O}_{2}$ adsorption processes [151-154].

As fossil fuel-based energy sources are in a constant decline, other alternative sources like nuclear energy are used instead, with the problem in this case of dangerous radioactive waste being generated. In addition, xenon and krypton are evolved as radionuclides from nuclear fuel reprocessing facilities. The high cost of cryogenic techniques enforces the search for less expensive solutions, such as porous materials, for the selective adsorption and separation of these gases [155]. The use of zeolites in devices like membranes was assessed experimentally and computationally by Forster et al. They concluded that channel and pore dimensions are key factors in the adsorption and separation of $\mathrm{Xe} / \mathrm{Kr}$ mixtures [156]. Additionally, other zeolites membranes have been tested for this application [157]. Furthermore, MOFs were experimentally and computationally screened for $\mathrm{Xe} / \mathrm{Kr}$ adsorption and separation SBMOF-1 being the most selective to 
Xe gas. Benchmark MOFs like UiO-66(Zr), MIL-10o(Fe), MIL-101(Cr) [158], and ultramicroporous MOFs [159] have also been used for these purposes with interesting results.

Adsorption in porous materials opens the way to other applications such as separations and sensors [16o]. In this sense, the separation capacities of gases and VOCs have been the subject of several works concerning both zeolites and MOFs. Actually, many authors have published the use of zeolites incorporated into membranes or filters for separation and purification technologies of gases and light hydrocarbons [161-163]. Excellent reviews have been published for separations in MOFs by Li et al. [164,165], and also the adsorption and separation processes in densified MOFs was outlined by Nune et al. [166] Moreover, MOFs have been incorporated into membranes to improve their performance, as reported by different authors [167-169], and separations of hydrocarbons and their isomers [170-172] as well as the separation of acetylene from $\mathrm{CO}_{2}$ have also been extensively studied [173-175].

\section{Adsorption of molecules of environmental interest in solution}

Although most of the examples shown in this chapter imply the adsorption of gas molecules into the cavities of a solid porous matrix (namely, zeolites or MOFs), there is also an increasing interest in developing advanced materials, which are able to efficiently adsorb toxic molecules in solution or sludges. In this sense, most of the examples reported in the literature so far have been focused on aqueous solutions, such as water purification, which has a tremendous impact of the health and welfare of society. In particular, great efforts are being directed towards the development of low-cost but selective adsorbent materials capable of retaining harmful substances such as, heavy metals, ionic species (ammonium, nitrate, phosphate, etc.), radionuclides, dyes and other organic molecules, as well as pharmaceuticals and personal care products, in their cavities [176].

In the last decades, zeolites have been explored as adsorbents in wastewater treatments due to their abundance in nature or low-cost preparation in this context. In particular, they exhibit high performance towards adsorption of cations (mainly, ammonium and heavy metals), based on their excellent ion exchange properties [177,178]. Moreover, different modifications, such as acid/base treatments or surfactant functionalizations [179], have been carried out in order to improve their selectivity towards adsorption of non-polar organic molecules or anions. In this sense, the use of 
metal-organic frameworks allows a more specific control over the final properties of the resulting materials, becoming more suitable candidates for the increasingly demanding needs in terms of water policy [180]. In fact, these 'laboratory materials' can be easily scaled-up and designed or functionalized according to the requirements of each application (tunable pore geometries, flexible skeletons, presence of reactive open metal sites, etc.) [181,182].

Some of the most relevant pollutants involved in water contamination are briefly discussed below, emphasizing the role that zeolites and MOFs have played in this context to date.

\section{Removal of heavy metals and ionic species}

As is well known, heavy metals are not biodegradable and tend to bioaccumulate in humans and other living organisms, resulting in severe diseases and disorders [183]. For this reason, the removal of these toxic species, mainly from wastewater and acid mine drainage, is of crucial importance. Both natural and synthetic zeolites have been extensively used in this field, as they exhibit excellent ion exchange properties and are inexpensive materials. In fact, they have been employed in the purification of aqueous solutions containing, among others, $\mathrm{Cr}(\mathrm{III}), \mathrm{Ni}(\mathrm{II}), \mathrm{Cu}(\mathrm{II}), \mathrm{Zn}(\mathrm{II}), \mathrm{Cd}(\mathrm{II})$ and $\mathrm{Pb}(\mathrm{II})$ [184-189]. Moreover, it has been demonstrated that a simple surfactant-modification of natural zeolites (e.g. Mordenite, clinoptilolite and chabazite-Ca) can significantly improve their adsorption capacity [190,191].

Metal-organic frameworks, have also been explored as trapping agents for different toxic cations (e.g. $\mathrm{Cu}(\mathrm{II}), \mathrm{Cd}(\mathrm{II}), \mathrm{Hg}(\mathrm{II})$ and $\mathrm{Pb}(\mathrm{II}))$ [192,193], while post-synthetic modifications of their skeletons, including thiol functionalization of HKUST-1 [194], thiourea functionalization of UiO-66- $\mathrm{NH}_{2}$ [195], and metalation of a Zn-based MOF containing a flexible tetracarboxylate linker [196] have been carried out in order to increase their adsorption properties in these toxic species.

Furthermore, some of these metal pollutants, such as $\mathrm{AsO}_{4}^{-}$or $\mathrm{CrO}_{4}^{-}$in their oxo-hydroxo anionic forms, occur in water. Indeed, some studies have been focused on the removal of different arsenic species by the zeolitic imidazole framework ZIF-8 [197,198], or different synthetic zeolites (e.g. Y, ZSM-5, Beta, Ferrierite, H-MFI-24 and H-MFI-9o in their $\mathrm{NH}_{4}^{+}$or $\mathrm{H}^{+}$forms) $[199,200]$, while chromate has been selectively trapped in the cavities of cationic metal-organic solid solutions [201].

Finally, adsorbent composites, based on zeolites or MOFs and other materials (cellulose acetate, nanoscale zero-valent iron, PVA polymer, 
magnetic nanoparticles, ceramic membrane ultrafiltration, etc.), are currently under development aiming to create hybrid systems with improved properties [202-207].

On the other hand, the discharge of effluents containing ionic species, such as ammonium, nitrates and phosphates, from domestic or industrial sources, can result in eutrophication of receiving water bodies, with a consequent environmental impact and ecosystem alteration. In this context, inorganic porous materials have been proposed as containers to keep these inorganic species trapped [208-209]. For example, phosphate ions, which are responsible for the algal bloom, have been selectively removed by using the synthetic zeolites HSZ 330 HUD and its $\mathrm{Al}^{3+}$ activated form [210], and the zirconium-based MOFs UiO-66 and UiO-66- $\mathrm{NH}_{2}$ [211].

\section{Removal of radionuclides and fission products}

The fast development of nuclear energy since the middle of the last century has also led to the accumulation of radionuclides and fission products in waste streams, becoming a serious concern with regard to environmental and public health. In this sense, zeolites and MOFs have emerged as promising candidates to satisfactorily handle these radioactive residues. Uranium, which is usually found in its hexavalent form, has been shown to be strongly adsorbed over different inorganic porous matrixes such as manganese oxide coated zeolites [212] and metal-organic frameworks exhibiting UiO-68 network topology [213]. Likewise, the remediation of aqueous solutions containing long-lived fission products (e.g. Tc-99 or Cs-135) is also needed. In fact, several studies have been carried out to date, employing four zeolites minerals (natural clinoptilolite, natural chabazite, natural Mordenite and synthetic Mordenite) to remove cesium from low-level radioactive liquid waste [214] and the efficient and selective uptake of pertechnetate ion $\left(\mathrm{TcO}_{4}^{-}\right)$by a cationic metal-organic framework material exhibiting open $\mathrm{Ag}^{+}$sites [215].

\section{Removal of dyes from the textile industry}

Dyes are also non-biodegradable pollutants commonly present in effluents from textile, paper, printing and other industries. The discharge of dye molecules into the environment generates serious problems not only from an aesthetic but also a toxicological point of view. Although 
commercial activated carbon is widely used as an adsorbent for colour removal, its relatively high cost and regeneration problems have encouraged the development of more profitable materials. Among them, zeolites are attractive adsorbents because of their low cost and easy availability. In fact, numerous studies have already demonstrated their adsorption capacity towards several cationic dyes (e.g. methylene blue, crystal violet or rhodamine B) in aqueous solution [216-218]. In addition, the use of modified zeolites (e.g. using hexamethylenediamine as surfactant) has allowed the successful removal of reactive azo dyes, such as Reactive Red 239 and Reactive Blue 250, which constitute over $50 \%$ of all textile dyes used in the industry [219].

The first example of a MOF being used as a dye adsorbent was published in 2010 [220]. In this work, two highly porous Cr-based MOFs were selected for the adsorptive removal of methyl orange from aqueous solutions. Since then, several examples using different framework topologies have been reported in the literature [221].

Moreover, recent studies have demonstrated that composites comprising a metal-organic framework (e.g. MIL-101, HKUST-1, ZIF-8, UiO-66, etc.) and other species (e.g. polyoxometalates, graphite oxide, polymers, etc.) are also promising candidates in terms of dye capture efficiency, outperforming in some cases the behaviour of commercial activated carbons [222-224]. Composites based on zeolites (e.g. natural clinoptilolite, NaZMS-5, etc.) loaded with titanium oxide are a new class of hybrid materials able to absorb and decompose efficiently different organic dyes by irradiation with light $\left[225^{-227}\right]$.

\section{Removal of pharmaceuticals and personal care products}

Finally, pharmaceuticals and personal care products (PPCPs) are considered emerging contaminants due to their widespread development and use in the last decades. Unfortunately, conventional wastewater treatment plants lack adequate purification processes to remove these organic contaminants. As result, pharmaceuticals and other related organic molecules are currently present, in detectable levels, in surface and ground water around industrial and residential communities, generating, among others, antibiotic-resistance issues. In this context, the research community and industry are currently working together in order to develop purification strategies able to remove these harmful substances from water supplies. For example, adsorption materials, including zeolites and metal-organic 
frameworks, can be considered a feasible solution as they are efficient, simple to design, and inexpensive. Indeed, different zeolites (such as, Y, Mordenite and $\mathrm{ZSM}-5$ ) have already been tested, showing positive results as absorbents of different pharmaceutically active compounds [228-229]. In addition, Zr-based MOFs have recently been used for the detection and removal of antibiotics [230], while well-known HKUST-1 proved to be a suitable sorbent for different parabens [231].

In summary, inorganic porous materials, namely zeolites and metalorganic frameworks, have attracted a great deal of attention for wastewater treatment mainly due to their high surface areas and versatility. On the one hand, zeolites seem to be promising candidates in those applications that require easy availability and low-cost materials. On the other hand, the possibility of designing and preparing MOFs 'à la carte', could become a clear advantage in more specific applications with higher budgets.

\section{Conclusion}

In recent years both zeolites and metal-organic frameworks have attracted a great deal of attention due to their exceptional properties (high porosity, high stability, tunable porosity and customizable skeletons), which make them promising candidates for industrial and environmental applications. In fact, different synthetic methodologies, including pre- and post-synthetic modifications, ion exchange processes, dealumination, desilication, controlled introduction of defects or metal cluster doping, have been recently developed in order to achieve increasingly demanding environmental requirements.

In this chapter, some of the most representative examples of adsorption in environmental and industrial applications have been compiled, including studies in both gas and liquid phase. On the one hand, the gas adsorption capability of both materials (zeolites and MOFs) has been discussed, trying to evaluate their potential as adsorbents in energy applications and/ or environment remediation processes $\left(\mathrm{CO}_{2}\right.$ capture and removal of toxic gases). On the other hand, these porous materials have also shown promising results regarding the adsorption of toxic molecules in solutions. In fact, some zeolites have already exhibited similar adsorption properties to those of commercial activated carbons, without the regeneration problems associated with these. In addition, MOFs, which can be easily designed and functionalized, are becoming suitable adsorbent materials in those water treatment processes that require the removal of more specific/difficult adsorbates. 
In conclusion, the excellent adsorption properties of zeolites and MOFs, linked to their ability to be designed in a rational way, make them appropriate candidates exhibiting promising perspectives towards this type of application.

\section{References}

[1] Atkins, P.W. The Elements of Physical Chemistry, Oxford University Press, 1994.

[2] IUPAC Compendium of Chemical Terminology, 2nd Ed., 1997.

[3] Sing, K.S.W, Gregg, S.J. Adsorption, Surface Area and Porosity, 2nd Ed., Academic Press, 1982.

[4] Brunauer, S., Deming, L.S., Deming, W.E., Teller, E.J. Am. Chem. Soc. 1940, 62, 1723.

[5] Reinoso, F.R. Chemistry and Physics of Carbon, Marcel Dekker, 1989.

[6] Brunauer, S., Emmett, P.H., Teller, E. J. Am. Chem. Soc. 1938, 6o, 309.

[7] Dubinin, M.M. Carbon 1985, 23, 373.

[8] Thielmann, F. J. Chromatogr. A 2004, 1037, 115.

[9] Rückriem, M., Enke, D., Hahn, T. Microp. Mesop. Mater. 2015, 209, 99.

[10] Mohammadi-Jam, S., Waters, K.E. Adv. Colloid Interface Sci. 2014, 212, 21.

[11] Conder, J.R., Young, C.L. Physicochemical Measurements by Gas Chromatography, Wiley, 1979.

[12] Papirer, E., Brendle, E., Ozil, F. Balard, H, Carbon 1999, 37, 1265.

[13] Papirer, E., Li, S., Balard, H., Jagiello, J, Carbon 1991, 29, 1135.

[14] Díaz, E., Ordóñez, S., Vega, A. J. Colloid Interface Sci. 2007, 305, 7.

[15] Voelkel, A., Strzemiecka, B, Adamska, K,, Milczewska, K.J. Chromatogr. A 2009, 1216, 1551.

[16] Garzón, F.J.L., García, M.D. Adsorption on New and Modified Inorganic Sorbents, Elsevier, 1996.

[17] Neumann, M.G.J. Chem. Educ. 1976, 53, 708.

[18] Helfferich, F. Ion Exchange, Dover Publications, 1995.

[19] Inglezakis, V.J.J. Colloid Interface Sci. 2005, 281, 68.

[2o] Ozekmekci, M., Salkic, G., Fellah, M.F. Fuel Process. Technol. 2015, 139, 49.

[21] Hoguet, J.C., Karagiannakis, G.P., Valla, J.A., Agrafiotis, C.C., Konstandopoulos, A.G. Int. J. Hydrogen Energy 2009, 34, 4953.

[22] Groen, J.C., Moulijn, J.A., Perez-Ramirez, J.J. Mater. Chem. 2006, 16, 2121.

[23] Groen, J.C., Peffer, L.A.A., Pérez-Ramírez, J. Microp. Mesop. Mater. 2003, 6o, 1.

[24] Beyer, H. in Post-Synthesis Modification I, Molecular Sieves Vol. 3, Chap. 3, Springer, 2002.

[25] Ogura, M., Shinomiya, S.Y., Tateno, J., Nara, Y., Nomura, M., Kikuchi, E., Matsukata, M. Appl. Catal., A 2001, 219, 33 .

[26] Suzuki, T., Okuhara, T. Microp. Mesop. Mater. 2001, 43, 83.

[27] Su, L., Liu, L., Zhuang, J., Wang, H., Li, Y., Shen, W., Xu, Y., Bao, X. Catal. Lett. 2003, 91, 155.

[28] Motz, J.L., Heinichen, H., Hölderich, W.F. J. Mol. Catal. A Chem. 1998, 136, 175.

[29] Janssen, A.H., Koster, A.J., de Jong, K.P. Angew. Chem. Int. Ed. 2001, 113, 1136.

[30] van Donk, S., Janssen, A.H., Bitter, J.H., de Jong, K.P. Catal. Rev. 2003, 45, 297.

[31] Pérez-Ramírez, J., Christensen, C.H., Egeblad, K., Christensen, C.H., Groen, J.C. Chem. Soc. Rev. 2008, 37, 2530.

[32] Egeblad, K., Christensen, C.H., Kustova, M., Christensen, C.H. Chem. Mater. 2008, 20, 946.

[33] Tao, Y., Kanoh, H., Abrams, L., Kaneko, K. Chem. Rev. 2006, 106, 896.

[34] Holm, M.S., Taarning, E., Egeblad, K., Christensen, C.H. Catal. Today 2011, 168, 3. 
[35] Schmidt, I., Madsen, C., Jacobsen. C.J.H. Inorg. Chem. 2000, 39, 2279.

[36] Tao, Y., Kanoh, H., Kaneko, K. Langmuir 2005, 21, 504.

[37] Schacht, S., Huo, Q., Voigt-Martin, I.G., Stucky, G.D., Schuth, F. Science 1996, 273, 768.

[38] Bagshaw, S.A., Baxter, N.I., Brew, D.R.M., Hosie, C.F., Yuntong, N., Jaenicke, S., Khuan, C.G. J. Mater. Chem. 2006, 16, 2235

[39] Xiao, F.S., Wang, L., Yin, C., Lin, K., Di, Y., Li, J., Xu, R., Su, D.S., Schlögl, R., Yokoi, T. Angew. Chem. Int. Ed. 2006, 45, 3090.

[40] Wei, Y., Parmentier, T.E., de Jong, K.P., Zečević, J. Chem. Soc. Rev. 2015, 44, 7234.

[41] Colombo, V., Montoro, C., Maspero, A., Palmisano, G., Masciocchi, N., Galli, S., Barea, E., Navarro, J.A.R. J. Am. Chem. Soc. 2012, 134, 12830.

[42] Colombo, V., Montoro, C., Maspero, A., Palmisano, G., Masciocchi, N., Galli, S., Barea, E., Navarro, J.A.R.J. Am. Chem. Soc. 2012, 134, 12630.

[43] Wei, Z., Yuan, D., Zhao, X., Sun, D., Zhou, H.C. Sci. China Chem. 2013, 56, 418.

[44] Deng, H., Doonan, C.J., Furukawa, H., Ferreira, R.B., Towne, J., Knobler, C.B., Wang, B., Yaghi, O.M. Science, 2010, 327, 846 .

[45] Wang, Z., Cohen, S.M. Chem. Soc. Rev. 2009, 38, 1315.

[46] Chui, S.S.Y., Lo, S.M.F., Charmant, J.P.H., Orpen, A.G., Williams, I.D. Science 1999, 283, 1148.

[47] López-Maya, E., Montoro, C., Colombo, V., Barea, E., Navarro, J.A.R. Adv. Funct. Mater. 2014, 24, 6130 .

[48] Fang, Z., Bueken, B., De Vos, D.E., Fischer, R.A. Angew. Chem. Int. Ed. 2015, 54, 7234.

[49] Bae, Y.S., Farha, O.K., Hupp, J.T., Snurr, R.Q.J. Mater. Chem. 2009, 19, 2131.

[50] Demessence, A., D’Alessandro, D.M., Foo, M.L., Long, J.R. J. Am. Chem. Soc. 2009, 131, 8784.

[51] McDonald, T.M., Mason, J.A., Kong, X., Bloch, E.D., Gygi, D., Dani, A., Crocellà, V., Giordanino, F., Odoh, S.O., Drisdell, W.S., et al. Nature, 2015, 519, 303.

[52] Montoro, C., Garcia, E., Calero, S., Perez-Fernandez, M.A., Lopez, A.L., Barea, E., Navarro, J.A.R.J. Mater. Chem. 2012, 22, 10155 .

[53] Gutov, O.V., Hevia, M.G., Escudero-Adán, E.C., Shafir, A. Inorg. Chem. 2015, 54, 8696.

[54] Wu, H., Chua, Y.S., Krungleviciute, V., Tyagi, M., Chen, P., Yildirim, T., Zhou, W. J. Am. Chem. Soc. 2013, 135, 10525 .

[55] Shearer, G.C., Chavan, S., Ethiraj, J., Vitillo, J.G., Svelle, S., Olsbye, U., Lamberti, C., Bordiga, S., Lillerud, K.P. Chem. Mater. 2014, 26, 4068.

[56] Cliffe, M.J., Wan, W., Zou, X., Chater, P.A., Kleppe, A.K., Tucker, M.G., Wilhelm, H., Funnell, N.P., Coudert, F.X., Goodwin, A.L. Nat. Commun. 2014, 5, 4176.

[57] López-Maya, E., Montoro, C., Rodríguez-Albelo, L.M., Aznar Cervantes, S.D., Lozano-Pérez, A., Cenís, J.A.L., Barea, E., Navarro, J.A.R. Angew. Chem. Int. Ed. 2015, 54, 6790.

[58] Vermoortele, F., Ameloot, R., Alaerts, L., Matthessen, R., Carlier, B., Fernandez, E.V.R., Gascon, J., Kapteijn, F., De Vos, D.E.J. Mater. Chem. 2012, 22, 10313.

[59] Gadipelli, S., Guo, Z. Chem. Mater. 2014, 23, 6333.

[6o] Banerjee, D., Kim, S.J., Wu, H., Xu, W., Borkowski, L., Li, J., Parise, J.B. Inorg. Chem. 2011, 50, 208.

[61] An, J., Geib, S.J., Rosi, N.L.J. Am. Chem. Soc. 2009, 131, 8376.

[62] Procopio, E.Q., Linares, F., Montoro, C., Colombo, V., Maspero, A., Barea, E., Navarro, J.A.R. Angew. Chem. Int. Ed. 2010, 49, 7308.

[63] Rodríguez-Albelo, L.M., López-Maya, E., Hamad, S., Ruiz-Salvador, A.R., Calero, S., Navarro, J.A.R. Nat. Commun. 2017, 8, 14457.

[64] He, T., Pachfule, P., Wu, H., Xu, Q., Chen, P. Nat. Rev. Mater. 2016, 1, 16059.

[65] Langmi, H.W., Walton, A., Al-Mamouri, M.M., Johnson, S.R., Book, D., Speight, J.D., Edwards, P.P., Gameson, I., Anderson, P.A., Harris, I.R.J. Alloys Compd. 2003, 356, 710.

[66] Dong, J., Wang, X., Xu, H., Zhao, Q., Li, J. Int. J. Hydrogen Energy 2007, 32, 4998. 
[67] Farha, O.K., Hupp, J.T., Wilmer, C.E., Eryazici, I., Snurr, R.Q., Gomez-Gualdron, D.A., Borah, B. US Patent 9216939, 2015.

[68] https://energy.gov/sites

[69] Rowsell, J.L.C., Yaghi, O.M. Angew. Chem. Int. Ed. 2005, 44, 4670.

[70] Ren, J., Musyoka, N.M., Langmi, H.W., Mathe, M., Liao, S. Int.J. Hydrogen Energy 2016, 42, 289.

[71] Thomas, K.M. Catal. Today 2007, 120, 389 .

[72] Thomas, K.M. Dalton Trans. 2009, 1487.

[73] Rosi, N.L., Eckert, J., Eddaoudi, M., Vodak, D.T., Kim, J., O’Keeffe, M., Yaghi, O.M. Science 2003, 300, 1127.

[74] Rowsell, J.L.C., Yaghi, O.M.J. Am. Chem. Soc. 2006, 128, 1304.

[75] Dincă, M., Han, W.S., Liu, Y., Dailly, A., Brown, C.M., Long, J.R. Angew. Chem. Int. Ed. 2007, 46, 1419 .

[76] Dincă, M., Long, J.R.J. Am. Chem. Soc. 2007, 129, 11172.

[77] Yang, S., Lin, X., Blake, A.J., Walker, G.S., Hubberstey, P., Champness, N.R., Schröder, M. Nat. Chem. 2009, 1, 487.

[78] Luo, J., Xu, H., Liu, Y., Zhao, Y., Daemen, L.L., Brown, C.J. Am. Chem. Soc. 2008, 130, 9626.

[79] Chen, B., Ma, S., Zapata, F., Lobkovsky, E.B., Yang, J., Arbor, A. Inorg. Chem. 20o6, 45, 5718.

[8o] Férey, G., Latroche, M., Serre, C., Millange, F., Loiseau, T., Percheron-Guégan, A. Chem. Commun. 2003, 2976.

[81] Chen, B., Ockwig, N.W., Millward, A.R., Contreras, D.S., Yaghi, O.M. Angew. Chem. Int. Ed. 2005, 44, 4745.

[82] Lin, X., Telepeni, I., Blake, A.J., Dailly, A., Brown, C.M., Simmons, J.M., Zoppi, M., Walker, G.S., Thomas, K.M., Mays, T.J., et al.J. Am. Chem. Soc. 2009, 131, 2159.

[83] Xiao, B., Wheatley, P.S., Zhao, X., Fletcher, A.J., Fox, S., Rossi, A.G., Megson, I.L., Bordiga, S., Regli, L., Thomas, K.M., et al.J. Am. Chem. Soc. 2007, 129, 1203.

[84] Volkringer, C., Meddouri, M., Loiseau, T., Guillou, N., Haouas, M., Taulelle, F., Audebrand, N., Latroche, M. Inorg. Chem. 2008, 47, 11892.

[85] Han, Z.B., Lu, R.Y., Liang, Y.F., Zhou, Y.L., Chen, Q., Zeng, M.H. Inorg. Chem. 2012, 51, 674.

[86] Farha, O.K., Yazaydın, Ö., Eryazici, I., Malliakas, C.D., Hauser, B.G., Kanatzidis, M.G., Nguyen, S.T., Snurr, R.Q., Hupp, J.T. Nat. Chem. 2010, 2, 944.

[87] Dincă, M., Dailly, A., Liu, Y., Brown, C.M., Neumann, D.A., Long, J.R.J. Am. Chem. Soc. 20o6, 128,16876 .

[88] He, Y., Zhou, W., Qian, G., Chen, B. Chem. Soc. Rev. 2014, 43, 5657.

[89] Lin, Y., Kong, C., Zhang, Q., Chen, L. Adv. Energy Mater. 2016, 1601296.

[9o] https://arpa-E.energy.gov/q=arpa-E-Programs/move

[91] Makal, T.A., Li, J.R., Lu, W., Zhou, H.C. Chem. Soc. Rev. 2012, 41, 7761.

[92] Rolniak, P.D., Kobayashi, R. AIChEJ. 1980, 26, 616.

[93] Menon, V.C., Komarneni, S. J. Porous Mater. 1998, 5, 43.

[94] Stockmeyer, R. US Patent 44959oo, 1985.

[95] Tate, K.L., Li, S., Yu, M., Carreon, M.A. Adsorption 2016, 23, 1.

[96] Wu, H., Simmons, J.M., Liu, Y., Brown, C.M., Wang, X. Sen, Shengqian, M., Peterson, V.K., Southon, P.D., Kepert, C.J., Zhou, H.C., et al. Chem. A Eur.J. 2010, 16, 5205.

[97] Li, B., Wen, H., Wang, H., Wu, H., Tyagi, M., Yildirim, T., Zhou, W., Chen, B.J. Am. Chem. Soc. 2014, 136, 6207 .

[98] Li, B., Wen, H.M., Wang, H., Wu, H., Yildirim, T., Zhou, W., Chen, B. Energy Environ. Sci. 2015, 8,2504 .

[99] Chang, G., Wen, H., Li, B., Zhou, W., Wang, H., Alfooty, K., Bao, Z., Chen, B. Cryst. Growth Des. 2016, 16, 3395 .

[100] Liu, J., Zou, R., Zhao, Y. Tetrahedron Lett. 2016, 57, 4873. 
[101] Mason, J.A., Veenstra, M., Long, J.R. Chem. Sci. 2014, 5, 32.

[102] Mason, J.A., Oktawiec, J., Taylor, M.K., Hudson, M.R., Rodriguez, J., Bachman, J.E., Gonzalez, M.I., Cervellino, A., Guagliardi, A., Brown, C.M., et al. Nature 2015, 357 .

[103] Alezi, D., Belmabkhout, Y., Suyetin, M., Bhatt, P.M., Weseliński, L.J., Solovyeva, V., Adil, K., Spanopoulos, I., Trikalitis, P.N., Emwas, A.H., et al.J. Am. Chem. Soc. 2015, 137, 13308.

[104] Jiang, J., Furukawa, H., Zhang, Y.B., Yaghi, O.M.J. Am. Chem. Soc. 2016, 138, 10244.

[105] Li, B., Wen, H.M., Cui, Y., Zhou, W., Qian, G., Chen, B. Adv. Mater. 2016, 28, 8819.

[106] Lin, J.M., He, C.T., Liu, Y., Liao, P.Q., Zhou, D.D., Zhang, J.P., Chen, X.M. Angew. Chem. Int. Ed. 2016, 55,4674 .

[107] Guo, Z., Wu, H., Srinivas, G., Zhou, Y., Xiang, S., Chen, Z., Yang, Y., Zhou, W., O'Keeffe, M., Chen, B. Angew. Chem. Int. Ed. 2011, 50, 3178.

[108] Zhou, W. Chem. Rec. 2010, 10, 200.

[109] Peng, Y., Krungleviciute, V., Eryazici, I., Hupp, J.T., Farha, O.K., Yildirim, T.J. Am. Chem. Soc. 2013, 135, 11887 .

[110] Li, B., Wen, H., Zhou, W., Xu, J.Q., Chen, B. Chem 2016, 1, 557.

[111] Chang, G., Li, B., Wang, H., Bao, Z., Yildirim, T., Yao, Z.Z., Xiang, S., Zhou, W., Chen, B. Chem. Commun. 2015, 51, 14789 .

[112] Liu, H., Chen, F., Bai, D., Jiao, J., Zhou, W., Yildirim, T., He, Y. Cryst. Growth Des. 2017, 17, 248.

[113] Song, C., Liu, H., Jiao, J., Bai, D., Zhou, W., Yildirim, T., He, Y. Dalton Trans. 2016, 45, 7559.

[114] Wang, Q., Song, X., Zhang, M., Liu, W., Bai, J. Cryst. Growth Des. 2016, 16, 6156.

[115] Intergovernmental Panel on Climate Change (IPCC). Climate Change, 2014.

[116] Dunne, J.A., Rao, M., Sircar, S., Gorte, R.J., Myers, A.L. Langmuir, 1996, 12, 5896.

[117] Coriani, S., Halkier, A., Rizzo, A., Ruud, K. Chem. Phys. Lett. 2000, 326, 269.

[118] Cavenati, S., Grande, C.A., Rodrigues, A.E.J. Chem. Eng. Data 2004, 49, 1095.

[119] Choudhary, V.R., Mayadevi, S. Langmuir, 1995, 12, 980.

[120] Harlick, P.J.E., Tezel, F.H. Sep. Purif. Technol. 2003, 33, 199.

[121] Saha, D., Bao, Z., Jia, F., Deng, S. Environ. Sci. Technol. 2010, 44, 1820.

[122] Samanta, A., Zhao, A., Shimizu, G.K.H., Sarkar, P., Gupta, R. Ind. Eng. Chem. Res. 2012, 51, 1438.

[123] Zhang, J., Singh, R., Webley, P.A. Microp. Mesop. Mater. 2008, 111, 478.

[124] Jadhav, P.D., Chatti, R.V., Biniwale, R.B., Labhsetwar, N.K., Devotta, S., Rayalu, S.S. Energy Fuels 2007, 21, 3555 .

[125] Su, F., Lu, C., Kuo, S.C., Zeng, W. Energy Fuels 2010, 24, 1441.

[126] Walton, K.S., Millward, A.R., Dubbeldam, D., Frost, H., Low, J.J., Yaghi, O.M., Snurr, R.Q. J. Am. Chem. Soc. 2008, 130, 406.

[127] Aprea, P., Caputo, D., Gargiulo, N., Iucolano, F., Pepe, F. J. Chem. Eng. Data 2010, 55, 3655.

[128] Yazaydin, O., Snurr, R.Q., Park, T.H., Koh, K., Liu, J., Levan, M.D., Benin, A.I., Jakubczak, P., Lanuza, M., Galloway, D.B., et al.J. Am. Chem. Soc. 2009, 131, 18198.

[129] Mason, J.A., Sumida, K., Herm, Z.R., Krishna, R., Long, J.R. Energy Environ. Sci. 2011, 4, 3030.

[130] Caskey, S.R., Wong-Foy, A.G., Matzger, A.J.J. Am. Chem. Soc. 2008, 130, 10870.

[131] Furukawa, H., Ko, N., Go, Y.B., Aratani, N., Choi, S.B., Choi, E., Yazaydin, A.O., Snurr, R.Q., O'Keeffe, M., Kim, J., et al. Science 2010, 329, 424.

[132] Choi, S., Watanabe, T., Bae, T.H., Sholl, D.S., Jones, C.W.J. Phys. Chem. Lett. 2012, 3, 1136.

[133] Rezaei, F., Rownaghi, A.A., Monjezi, S., Lively, R.P., Jones, C.W. Energy Fuels 2015, 29, 1.

[134] Liu, Y., Bisson, T.M., Yang, H., Xu, Z. Fuel Process. Technol. 2010, 91, 1175.

[135] Barea, E., Montoro, C., Navarro, J.A.R. Chem. Soc. Rev. 2014, 43, 5419.

[136] Deng, H., Yi, H., Tang, X., Yu, Q., Ning, P., Yang, L. Chem. Eng.J. 2012, 188, 77.

[137] Britt, D., Tranchemontagne, D., Yaghi, O.M. PNAS 2008, 105, 11623.

[138] Dathe, H., Haider, P., Jentys, A., Lercher, J.A.J. Phys. Chem. B 2006, 110, 26024. 
[139] McKinlay, A.C., Xiao, B., Wragg, D.S., Wheatley, P.S., Megson, I.L., Morris, R.E.J. Am. Chem. Soc. 2008, 130, 10440 .

[140] Xiao, B., Wheatley, P.S., Zhao, X., Fletcher, A.J., Fox, S., Rossi, A.G., Megson, I.L., Bordiga, S., Regli, L., Thomas, K.M., et al.J. Am. Chem. Soc. 2007, 129, 1203.

[141] McKinlay, A.C., Eubank, J.F., Wuttke, S., Xiao, B., Wheatley, P.S., Bazin, P., Lavalley, J.C., Daturi, M., Vimont, A., De Weireld, G., et al. Chem. Mater. 2013, 25, 1592.

[142] Ebrahim, A.M., Levasseur, B., Bandosz, T.J. Langmuir 2013, $29,168$.

[143] Petit, C., Bandosz, T.J. Dalton Trans. 2012, 41, 4027.

[144] Montoro, C., Linares, F., Quartapelle Procopio, E., Senkovska, I., Kaskel, S., Galli, S., Masciocchi, N., Barea, E., Navarro, J.A.R.J. Am. Chem. Soc. 2011, 133, 11888.

[145] Padial, N.M., Quartapelle Procopio, E., Montoro, C., López, E., Oltra, J.E., Colombo, V., Maspero, A., Masciocchi, N., Galli, S., Senkovska, I., et al. Angew. Chem. Int. Ed. 2013, 52, 8290.

[146] Ferreira, D., Boaventura, M., Bárcia, P., Whitley, R.D., Mendes, A. Ind. Eng. Chem. Res. 2016, 55,722 .

[147] Hamed, H.H. Int.J. Sci. Eng. Res. 2015, 6, 597.

[148] Wu, C.W., Vemula, R.R., Kothare, M.V., Sircar, S. Ind. Eng. Chem. Res. 2016, 55, 4676.

[149] Wu, C., Kothare, M.V, Sircar, S. Ind. Eng. Chem. Res. 2014, 53, 12428.

[150] DeCoste, J.B., Weston, M.H., Fuller, P.E., Tovar, T.M., Peterson, G.W., LeVan, M.D., Farha, O.K. Angew. Chem. Int. Ed. 2014, 53, 14092.

[151] Bloch, E.D., Queen, W.L., Hudson, M.R., Mason, J.A., Xiao, D.J., Murray, L.J., Flacau, R., Brown, C.M., Long, J.R. Angew. Chem. Int. Ed. 2016, 55, 8605.

[152] Wang, C.Y., Wang, L., Belnick, A., Wang, H., Li, J., Lueking, A.D. Chem. Eng. Sci. 2017, 165, 122.

[153] Xiao, D.J., Gonzalez, M.I., Darago, L.E., Vogiatzis, K.D., Haldoupis, E., Gagliardi, L., Long, J.R. J. Am. Chem. Soc. 2016, 138, 7161.

[154] Zhang, W., Banerjee, D., Liu, J., Schaef, H.T., Crum, J.V., Fernandez, C.A., Kukkadapu, R.K., Nie, Z., Nune, S.K., Motkuri, R.K., et al. Adv. Mater. 2016, 28, 3572.

[155] Banerjee, D., Simon, C.M., Plonka, A.M., Motkuri, R.K., Liu, J., Chen, X., Smit, B., Parise, J.B., Haranczyk, M., Thallapally, P.K. Nat. Commun. 2016, 7, 11831.

[156] Lawler, K.V., Sharma, A., Alagappan, B., Forster, P.M. Microp. Mesop. Mater. 2016, 222, 104.

[157] Feng, X., Zong, Z., Elsaidi, S.K., Jasinski, J.B., Krishna, R., Thallapally, P.K., Carreon, M.A. J. Am. Chem. Soc. 2016, 138, 9791.

[158] Lee, S.J., Yoon, T.U., Kim, A.R., Kim, S.Y., Cho, K.H., Hwang, Y.K., Yeon, J.W., Bae, Y.S. J. Hazard. Mater. 2016, 320, 513 .

[159] Mohamed, M.H., Elsaidi, S.K., Pham, T., Forrest, K.A., Schaef, H.T., Hogan, A., Wojtas, L., $\mathrm{Xu}, \mathrm{W}$., Space, B., Zaworotko, M.J., et al. Angew. Chem. Int. Ed. 2016, 55, 8285.

[16o] Yi, F.Y., Chen, D., Wu, M.K., Han, L., Jiang, H.L. ChemPlusChem 2016, 81, 675 .

[161] Kosinov, N., Gascon, J., Kapteijn, F., Hensen, E.J.M.J. Membrane Sci. 2016, 499, 65.

[162] Bellussi, G., Millini, R., Pollesel, P., Perego, C. New J. Chem. 2016, 40, 4061.

[163] Khulbe, K.C., Matsuura, T., Feng, C.Y., Ismail, A.F., Himeno, S., Tomita, T., Shujiki, K., Yoshida, S., Burton, A., Sherman, J.D., et al. RSC Adv. 2016, 6, 42943.

[164] Li, J.R., Kuppler, R.J., Zhou, H.C. Chem. Soc. Rev. 2009, 38, 1477.

[165] Li, J., Sculley, J., Zhou, H. Chem. Rev. 2012, 112, 869.

[166] Nandasiri, M.I., Jambovane, S.R., McGrail, B.P., Schaef, H.T., Nune, S.K. Coord. Chem. Rev. 2016, 311, 38 .

[167] Qiu, S., Xue, M., Zhu, G. Chem. Soc. Rev. 2014, 43, 6116.

[168] Melgar, V.M.A., Kim, J., Othman, M.R.J. Ind. Eng. Chem. 2015, 28, 1.

[169] Kang, Z., Fan, L., Sun, D. J. Mater. Chem. A 2017.

[170] Cadiau, A., Adil, K., Bhatt, P.M., Belmabkhout, Y., Eddaoudi, M. Science, 2016, 353, 137. 
[171] He, Y.P., Zhou, N., Tan, Y.X., Wang, F., Zhang, J.J. Solid State Chem. 2016, 238, 241.

[172] Liu, H., He, Y., Jiao, J., Bai, D., Chen, D.L., Krishna, R., Chen, B. Chem. Eur. J. 2016, 22, 14988.

[173] Chang, G., Li, B., Wang, H., Hu, T., Bao, Z., Chen, B. Chem. Commun. 2016, 52, 3494.

[174] Foo, M.L., Matsuda, R., Hijikata, Y., Krishna, R., Sato, H., Horike, S., Hori, A., Duan, J., Sato, Y., Kubota, Y., et al.J. Am. Chem. Soc. 2016, 138, 3022.

[175] Luo, F., Yan, C., Dang, L., Krishna, R., Zhou, W., Wu, H., Dong, X., Han, Y., Hu, T.L., O’Keeffe, M., et al.J. Am. Chem. Soc. 2016, 138, 5678 .

[176] Gupta, V.K., Carrott, P.J.M., Ribeiro Carrott, M.M.L., Suhas. Crit. Rev. Environ. Sci. Technol. 2009, 39, 783 .

[177] Wang, S., Peng, Y. Chem. Eng.J. 2010, 156, 11.

[178] Misaelides, P. Microp. Mesop. Mater. 2011, 144, 15 .

[179] Bowman, R.S. Microp. Mesop. Mater. 2003, 61, 43.

[180] Khan, N.A., Hasan, Z., Jhung, S.H.J. Hazard. Mater. 2013, 244, 444.

[181] Kitagawa, S., Kitaura, R., Noro, S. Angew. Chem. Int. Ed. 2004, 43, 2334.

[182] Rowsell, J.L.C., Yaghi, O.M. Microp. Mesop. Mater. 2004, 73, 3.

[183] Jaishankar, M., Tseten, T., Anbalagan, N., Mathew, B.B., Beeregowda, K.N. Interdiscip. Toxicol. 2014, 7, 60 .

[184] Álvarez-Ayuso, E., García-Sánchez, A., Querol, X. Water Res. 2003, 37, 4855.

[185] Babel, S., Kurniawan, T.A.J. Hazard. Mater. 2003, 97, 219.

[186] Perić, J., Trgo, M., Vukojević Medvidović, N. Water Res. 2004, 38, 1893.

[187] Erdem, E., Karapinar, N., Donat, R. J. Colloid Interface Sci. 2004, 280, 309.

[188] Günay, A., Arslankaya, E., Tosun, I. J. Hazard. Mater. 2007, 146, 362.

[189] Motsi, T., Rowson, N.A., Simmons, M.J.H. Int. J. Miner. Process. 2009, 92, 42.

[19o] Chutia, P., Kato, S., Kojima, T., Satokawa, S. J. Hazard. Mater. 2009, 162, 204.

[191] Zeng, Y., Woo, H., Lee, G., Park, J. Microp. Mesop. Mater. 2010, 130, 83.

[192] Jamali, A., Tehrani, A.A., Shemirani, F., Morsali, A. Dalton Trans. 2016, 45, 9193.

[193] Fang, Q.R., Yuan, D.Q., Sculley, J., Li, J.R., Han, Z.B., Zhou, H.C. Inorg. Chem. 2010, 49, 11637.

[194] Ke, F., Qiu, L.G., Yuan, Y.P., Peng, F.M., Jiang, X., Xie, A.J., Shen, Y.H., Zhu, J.F. J. Hazard. Mater. 2011, 196, 36 .

[195] Saleem, H., Rafique, U., Davies, R.P. Microp. Mesop. Mater. 2016, 221, 238.

[196] Chakraborty, A., Bhattacharyya, S., Hazra, A., Ghosh, A.C., Maji, T.K. Chem. Commun. 2016, $5^{2,1 .}$

[197] Wu, Y., Zhou, M., Zhang, B., Wu, B., Li, J., Qiao, J., Guan, X., Li, F. Nanoscale 2014, 6, 1105.

[198] Jian, M., Liu, B., Zhang, G., Liu, R., Zhang, X. Colloids Surf. A 2015, 465, 67.

[199] Shevade, S., Ford, R.G. Water Res. 2004, 38, 3197.

[200] Chutia, P., Kato, S., Kojima, T., Satokawa, S. J. Hazard. Mater. 2009, 162, 440.

[201] Fei, H., Han, C.S., Robins, J.C., Oliver, S.R.J. Chem. Mater. 2013, 25, 647.

[202] Ji, F., Li, C., Tang, B., Xu, J., Lu, G., Liu, P. Chem. Eng. J. 2012, 209, 325.

[203] Kim, S.A., Kamala-Kannan, S., Lee, K.J., Park, Y.J., Shea, P.J., Lee, W.H., Kim, H.M., Oh, B.T. Chem. Eng.J. 2013, 217, 54.

[204] Rad, L.R., Momeni, A., Ghazani, B.F., Irani, M., Mahmoudi, M., Noghreh, B. Chem. Eng. J. 2014, 256, 119 .

[205] Ricco, R., Konstas, K., Styles, M.J., Richardson, J.J., Babarao, R., Suzuki, K., Scopece, P., Falcaro, P. J. Mater. Chem. A 2015, 3, 19822.

[206] Ghorbani-Kalhor, E. Microchim. Acta 2016, 183, 2639.

[207] Yin, N., Wang, K., Wang, L., Li, Z. Chem. Eng.J. 2016, 306, 619.

[208] Huang, H., Xiao, X., Yan, B., Yang, L.J. Hazard. Mater. 2010, 175, 247.

[209] Bhatnagar, A., Sillanpää, M.A. Chem. Eng.J. 2011, 168, 493.

[210] Onyango, M.S., Kuchar, D., Kubota, M., Matsuda, H. Ind. Eng. Chem. Res. 2007, 46, 894. 
[211] Lin, K.Y.A., Chen, S.Y., Jochems, A.P. Mater. Chem. Phys. 2015, 16o, 168.

[212] Han, R., Zou, W., Wang, Y., Zhu, L. J. Environ. Radioact. 2007, 93, 127.

[213] Carboni, M., Abney, C.W., Liu, S., Lin, W. Chem. Sci. 2013, 4, 2396.

[214] Borai, E.H., Harjula, R., Malinen, L., Paajanen, A.J. Hazard. Mater. 2009, 172, 416.

[215] Sheng, D., Zhu, L., Xu, C., Xiao, C., Wang, Y., Wang, Y., Chen, L., Diwu, J., Chen, J., Chai, Z., et al. Environ. Sci. Technol. 2017, 51, 3471.

[216] Wang, S., Li, H., Xu, L. J. Colloid Interface Sci. 2006, 295, 71.

[217] Wang, S., Zhu, Z.H.J. Hazard. Mater. 2006, 136, 946.

[218] Han, R., Zhang, J., Han, P., Wang, Y., Zhao, Z., Tang, M. Chem. Eng.J. 20o9, 145, 496.

[219] Alver, E., Metin, A.Ü. Chem. Eng.J. 2012, 200, 59.

[220] Haque, E., Lee, J.E., Jang, I.T., Hwang, Y.K., Chang, J.S., Jegal, J., Jhung, S.H.J. Hazard. Mater. 2010, 181, 535 .

[221] Hasan, Z., Jhung, S.H.J. Hazard. Mater. 2015, 283, 329.

[222] Li, L., Liu, X.L., Geng, H.Y., Hu, B., Song, G.W., Xu, Z.S. J. Mater. Chem. A 2013, 1, 10292.

[223] Huo, J., Marcello, M., Garai, A., Bradshaw, D. Adv. Mater. 2013, 25, 2717.

[224] Yan, A.X., Yao, S., Li, Y.G., Zhang, Z.M., Lu, Y., Chen, W.L., Wang, E.B. Chem. Eur. J. 2014, 20, 6927.

[225] Huang, M., Xu, C., Wu, Z., Huang, Y., Lin, J., Wu, J. Dye. Pigment. 2008, 77, 327.

[226] Nikazar, M., Gholivand, K., Mahanpoor, K. Desalination 2008, 219, 293.

[227] Zhang, W., Wang, K., Yu, Y., He, H. Chem. Eng.J. 2010, 163, 62.

[228] Martucci, A., Pasti, L., Marchetti, N., Cavazzini, A., Dondi, F., Alberti, A. Microp. Mesop. Mater. 2012, 148, 174.

[229] Blasioli, S., Martucci, A., Paul, G., Gigli, L., Cossi, M., Johnston, C.T., Marchese, L., Braschi, I. J. Colloid Interface Sci. 2014, 419, 148.

[230] Wang, B., Lv, X.L., Feng, D., Xie, L.H., Zhang, J., Li, M., Xie, Y., Li, J.R., Zhou, H.C.J. Am. Chem. Soc. 2016, 138, 6204 .

[231] Rocío-Bautista, P., Martínez-Benito, C., Pino, V., Pasán, J., Ayala, J.H., Ruiz-Pérez, C., Afonso, A.M. Talanta 2015, 139, 13 . 